\title{
Role of Copper and Cholesterol Association in the Neurodegenerative Process
}

\author{
Nathalie Arnal, ${ }^{1}$ Gustavo R. Morel, ${ }^{1}$ María J. T. de Alaniz, \\ Omar Castillo, ${ }^{2}$ and Carlos A. Marra ${ }^{1}$ \\ ${ }^{1}$ INIBIOLP (Instituto de Investigaciones Bioquímicas de La Plata), CCT La Plata, CONICET-UNLP, Cátedra de Bioquímica y \\ Biología Molecular, Facultad de Ciencias Médicas, Universidad Nacional de La Plata, 60 y 120 (1900) La Plata, Argentina \\ ${ }^{2}$ CIC (Centro de Investigaciones Cardiovasculares), CCT La Plata, CONICET-UNLP, Facultad de Ciencias Médicas, \\ Universidad Nacional de La Plata, 60 y 120 (1900) La Plata, Argentina
}

Correspondence should be addressed to Carlos A. Marra; contactocarlos@hotmail.com

Received 7 July 2013; Revised 5 September 2013; Accepted 5 September 2013

Academic Editor: Rosanna Squitti

Copyright (c) 2013 Nathalie Arnal et al. This is an open access article distributed under the Creative Commons Attribution License, which permits unrestricted use, distribution, and reproduction in any medium, provided the original work is properly cited.

Age is one of the main factors involved in the development of neurological illnesses, in particular, Alzheimer, and it is widely held that the rapid aging of the world population is accompanied by a rise in the prevalence and incidence of Alzheimer disease. However, evidence from recent decades indicates that $\mathrm{Cu}$ and $\mathrm{Cho}$ overload are emerging causative factors in neurodegeneration, a hypothesis that has been partially investigated in experimental models. The link between these two variables and the onset of Alzheimer disease has opened up interesting new possibilities requiring more in-depth analysis. The aim of the present study was therefore to investigate the effect of the association of $\mathrm{Cu}+\mathrm{Cho}(\mathrm{CuCho})$ as a possible synergistic factor in the development of an Alzheimer-like pathology in Wistar rats. We measured total- and nonceruloplasmin-bound $\mathrm{Cu}$ and $\mathrm{Cho}$ (free and sterified) contents in plasma and brain zones (cortex and hippocampus), markers of oxidative stress damage, inflammation, and programmed cell death (caspase-3 and calpain isoforms). The ratio beta-amyloid (1-42)/(1-40) was determined in plasma and brain as neurodegenerative biomarker. An evaluation of visuospatial memory (Barnes maze test) was also performed. The results demonstrate the establishment of a prooxidative and proinflammatory environment after $\mathrm{CuCho}$ treatment, hallmarked by increased TBARS, protein carbonyls, and nitrite plus nitrate levels in plasma and brain zones (cortex and hippocampus) with a consequent increase in the activity of calpains and no significant changes in caspase- 3 . A simultaneous increase in the plasma A $\beta 1-42 / \mathrm{A} \beta 1-40$ ratio was found. Furthermore, a slight but noticeable change in visuospatial memory was observed in rats treated with CuCho. We conclude that our model could reflect an initial stage of neurodegeneration in which $\mathrm{Cu}$ and Cho interact with one another to exacerbate neurological damage.

\section{Introduction}

The aging of the world population is being accompanied by a rise in the prevalence and incidence of Alzheimer disease (AD) and other neurodegenerative illnesses. In the USA, the number of patients with $\mathrm{AD}$ is expected to increase to 13 million by 2050 and in the European Union (EU) to over 4 million [1]. The mortality rate of $\mathrm{AD}$ is second only to cancer and stroke. Epidemiologic data indicates that the world population will have grown considerably by 2025 and the percentage of elderly people will be significantly higher [2]. Since age is one of the major risk factors in the development of $\mathrm{AD}$, it is expected that the incidence of this disease will also increase. However, experimental evidence detailed in a review by Brewer indicates that other factors in addition to age could play a critical role [3] in the development of diseases such as Alzheimer and that the contribution of inorganic copper $(\mathrm{Cu})$ has been underestimated. It is widely known that more than $95 \%$ of AD cases are sporadic and only 2$7 \%$ are genetically determined [4]. Thus, any environmental factors likely to have an etiopathogenic role in AD should be investigated.

Though $\mathrm{Cu}$ is essential to human health, $\mathrm{Cu}$ overload has been associated with mental decline [5] and particularly with $\mathrm{AD}$ development $[3,6,7]$. Data from Squitti's group specifically demonstrated that free $\mathrm{Cu}$ (also known as NCBC 
or nonceruloplasmin-bound $\mathrm{Cu}$ ) is elevated in the blood of $\mathrm{AD}$ patients, negatively correlates with cognition, and predicts the rate of loss of cognition [8-10]. More recently, our group corroborated these findings in an independent human cohort and demonstrated that increased NCBC has a direct impact on the disease duration [11]. We also proposed the $\mathrm{NCBC} /$ ceruloplasmin ratio as a predictive marker of risk for the first-degree relatives of AD patients. Sparks and Schreurs [12] first demonstrated that $\mathrm{Cu}$ supplementation in drinking water given to rabbits under a diet with excess cholesterol (Cho) produced an induction of $\beta$-amyloid plaques and a learning deficit. In addition, $\mathrm{Lu}$ et al. reported that trace amounts of $\mathrm{Cu}$ activate the apoptotic cascade and exacerbate beta amyloid-induced neurotoxicity in Cho-fed mice through a TNF-mediated inflammatory pathway $[13,14]$. Very recently, Brewer has reviewed the theory of inorganic $\mathrm{Cu}$ toxicity in Alzheimer disease as a causative factor in cognitive loss [6]. However, the question of how inorganic $\mathrm{Cu}$ might trigger a neurodegenerative process is still a matter of debate [15].

The degree of exposure of human populations to $\mathrm{Cu}$ is also a controversial issue. There is little data on $\mathrm{Cu}$ overload in humans since most of the available evidence (experimental or epidemiological) was obtained from animal models. However, the regulatory framework for chronic $\mathrm{Cu}$ exposure in large human populations indicates that pollution, drinking water, and dietary $\mathrm{Cu}$-containing supplements are the main sources of exposure $[6,16]$. The dietary reference intake for people in the USA, United Kingdom, Europe, and Australia varies from 0.16 to 0.98 (Estimated Average Requirements) EAR or (Recommended Dietary Allowance) RDA expressed in $\mathrm{mg} \mathrm{Cu} / \mathrm{kg}$ body weight, with considerable variations as a function of age. The (Population Reference Intake) PRI was reported between 0.3 and $1.5 \mathrm{mg} \mathrm{Cu} / \mathrm{kg}$ body weight [16]; however, these limits were largely surpassed in many circumstances such as ingestion of fish, bivalves, or contaminated drinking water $[3,17]$. In accumulated data on 280 samples of household drinking water all across North America, 72\% of the samples have $\mathrm{Cu}$ levels above those enhancing $\mathrm{AD}$ in experimental models [3]. The content of inorganic $\mathrm{Cu}$ in dietary supplements can be as high as $3 \mathrm{mg} /$ pill (approx. $2 \mathrm{mg}$ above the EAR or RDA). Furthermore, we and others have demonstrated significantly higher $\mathrm{Cu}$ levels in plasma of women using Cu-IUDs and in blood samples from farmers working with $\mathrm{Cu}$-based pesticides [17-19]. Most importantly, we found alterations in $\mathrm{Cu}$ homeostatic biomarkers in neurodegenerative patients and their first-degrees relatives [11].

Fat ingestion has also been linked to AD prevalence [20]. Specifically, Cho has been associated with oxidative stress and $\mathrm{AD}$ development $[21,22]$, with most of the experimental evidence emerging from exploration of the role of Cho in $\beta$ amyloid formation [23]. Despite the paucity of epidemiological data from human studies, it is reasonable to assume that Cho plays at least some role in learning and memory and is associated with $\mathrm{AD}$ pathogenesis [24]. Of particular interest is evidence showing that $\mathrm{Cu}$ greatly exacerbates cognitive decline in those people included in the highest quintile of fat ingestion [25]. Experimental evidence obtained from rabbit and mouse models suggests that the association of
$\mathrm{Cu}$ and $\mathrm{Cho}$ can be risk factor for AD development [12-14]. Moreover, it was hypothesized that $\mathrm{Cu}$ could oxidize Cho, generating substances toxic to the brain [3].

However, the mechanism of action of $\mathrm{Cu}$ and $\mathrm{Cho}$ in $\mathrm{AD}$ incidence and development is poorly understood and requires further investigation. Thus, the aim of this work was to study the effects of $\mathrm{Cu}$ and Cho association on the two main brain areas affected in $\mathrm{AD}$, cortex and hippocampus, using a model of Wistar rats. Specifically, we aimed to determine for each nutritional supplement alone or in combination (i) the capacity to install oxidative/nitrative damage; (ii) changes in the levels of the main antioxidant molecules (glutathione and $\alpha$-tocopherol); (iii) the possible development of a proinflammatory condition by analyzing the concentration of prostaglandins PGE2 and PGF2 $\alpha$; (iv) the activities of the two main protease systems associated with programmed cell death, caspase- 3 and calpains ( $\mu$ - and $\mathrm{m}$-); and (v) possible changes in visuospatial memory as assessed by means of the Barnes maze test.

Our findings could be useful in further investigating the mechanisms underlying the neurodegenerative process and also in localizing putative targets for preventive interventions associated with endogenous and/or exogenous causative factors such as $\mathrm{Cu}$ and $\mathrm{Cho}$, alone or in combination.

\section{Material and Methods}

2.1. Chemicals. All chemicals used were of analytical grade and obtained from Sigma Chem. Co. (Buenos Aires, Argentina or USA), Merck (Darmstadt, Germany), and Carlo Erba (Milan, Italy).

2.2. Animals and Treatments. Certified pathogen-free male Wistar rats were used. The rats were maintained at a controlled temperature $\left(25^{\circ} \mathrm{C}\right)$ and relative humidity of $60 \%$ with forced ventilation, under a normal photoperiod of $12 \mathrm{~h}$ darkness and $12 \mathrm{~h}$ light. The health of the animals was monitored in accordance with the internationally recommended practices of the (Institute of Laboratory Animal Resources, Commission of Life Sciences, National Research Council) ILAR. Solid food and drinking water were provided ad libitum. The diets for the experiments were prepared in our laboratory according to the recommendations for Wistar rats [26]. All procedures for handling the animals followed the NIH regulations [27]. The experimental protocol was reviewed and approved by (Bioethics Committee of the Faculty of Medical Sciences, UNLP) COBIMED under the code \# 00382/11.

2.3. Experimental Protocols. Rats (21 days old) were randomly assigned (ten animals per group) to the protocols detailed as follows and treated during eight weeks. The control group (C) was maintained on lab-prepared pellets as recommended for normal growth, containing $7 \mathrm{ppm}$ of $\mathrm{Cu}[28,29]$. The $\mathrm{Cu}-$ supplemented experimental group $(\mathrm{Cu})$ was fed on control pellets and tap water supplemented with $3 \mathrm{mg} / \mathrm{L}$ (or ppm) of $\mathrm{Cu}$ in the form of ultrapure $\mathrm{CuSO}_{4}$ (Merck, Darmstadt, Germany), the Cho-supplemented group (Cho) was fed on pellets containing $2 \%(\mathrm{~W} / \mathrm{W})$ of Cho (87\% pure) (obtained from 
Saporiti SRL, Buenos Aires, Argentina), and the $\mathrm{Cu}+$ Chosupplemented group (CuCho) was simultaneously treated with $\mathrm{Cu}$ in water $+\mathrm{Cho}$ in food. Rats were monitored during the experimental period to observe their behavior, quantify water, and food consumption and determine their body weight gain. Total $\mathrm{Cu}$ concentration in tap water supplemented with $\mathrm{CuSO}_{4}$ was determined by means of atomic absorption methodology and was $3.42 \pm 0.21 \mathrm{ppm}$ (means of all daily measurements along the experimental period). Considering that each animal imbibed between $4.9 \pm 0.4$ and $15.0 \pm 1.1 \mathrm{~mL}$ water/day (at the beginning and the end of the protocol, resp.), a maximum of 0.01 to $0.05 \mathrm{mg} \mathrm{Cu}$ /day was acquired from water (a dose equivalent to 0.06 and $0.18 \mathrm{mg}$ $\mathrm{Cu} / \mathrm{Kg}$ live animal, resp.). Linear regression curves and ANOVA test for $\mathrm{Cu}$ content in food demonstrated that there were no significant variations between the 6 preparations used for the experiments $(7.22 \pm 0.31 \mathrm{ppm}$ or $\mathrm{mg} \mathrm{Cu} / \mathrm{Kg}$ diet). Fe and $\mathrm{Zn}$ content (determined by atomic absorption spectrometry) were the same in all preparations $(45.9 \pm 1.8$ and $66.6 \pm 2.0 \mathrm{ppm}$, resp.). Ingestion of solid food along the experiments varied from $11.6 \pm 0.8$ to $29.7 \pm 2.8 \mathrm{~g} / \mathrm{rat}$, implying that the oral ingestion of $\mathrm{Cu}$ was in the range of 0.08 to $0.21 \mathrm{mg}$ $\mathrm{Cu} /$ day/rat $(0.90$ to $1.21 \mathrm{mg} \mathrm{Cu} / \mathrm{Kg}$ live animal, a mean of $1.06 \pm 0.11 \mathrm{mg} \mathrm{Cu} / \mathrm{Kg})$.

2.4. Sample Collection. At the end of the treatments, animals were deeply anesthetized with ketamine $(70 \mathrm{mg} / \mathrm{Kg})$ and xylazine $(5 \mathrm{mg} / \mathrm{Kg}$ ) applied intramuscularly and then sacrificed by decapitation. Brains were rapidly taken out and dissected in two zones, cortex and hippocampus, using the atlas of Paxinos and Watson [30] as a guide for tissue dissection and a Binocular Stereoscopic Arcano Ztx-1065 Microscope (Instrumental Pasteur, Buenos Aires, Argentina). Both brain regions were washed, weighed, and homogenized using a buffer Tris/ $\mathrm{HCl}(10 \mathrm{mM} \mathrm{pH}$ 7.4) with sucrose (70 mM), mannitol $(230 \mathrm{mM})$, ethylenediaminetetraacetic acid (EDTA) (1 mM), and dithiothreitol (DTT) (1 mM).

2.5. Atomic Absorption Measurements. Aliquots of sample were digested with a mixture of $4 \mathrm{~mL}$ of $\mathrm{HNO}_{3}$ (c) and $1 \mathrm{~mL} \mathrm{HClO}_{4}$ (Aldrich or Sigma Chem. Co., Buenos Aires, Argentina) by heating at $120^{\circ} \mathrm{C}$ for $80 \mathrm{~min}$ in a mineralization block [31]. The digests were cooled, diluted with ultrapure water $(18 \mathrm{~m} \Omega \mathrm{cm}$, Carlo Erba, Milan, Italy), and ultrafiltered by a $0.22 \mu \mathrm{m}$ Millipore membrane (Milli-Q Purification System, from Millipore, CA, USA). Ultrafiltered dissolutions were directly aspirated into the flame of a Perkin-Elmer 1100 B Spectrophotometer equipped with a Perkin-Elmer cathode lamp (Perkin-Elmer Corp., Norwalk, CT, USA) at a spectral width of $1 \mathrm{~nm}$. Standard solutions of $100 \mathrm{ppm}$ from HCR Inc. (QuimiNet, Buenos Aires, Argentina) were used for $\mathrm{Zn}$ and $\mathrm{Fe}$. $\mathrm{Cu}$ determinations were calibrated with a standard solution $(200 \mathrm{ppm})$ of $\mathrm{Cu}\left(\mathrm{NO}_{3}\right)_{2}$ in $\mathrm{HNO}_{3} 0.5 \mathrm{~N}$ (Tritrisol from Merck Co., Darmstadt, Germany). All measurements were carried out in peak height mode $(324.7 \mathrm{~nm}$ line). The intra- $[(\mathrm{SD} / \mathrm{x}) \cdot 100]$ and inter- $[(\Delta \mathrm{SD} / \Delta \mathrm{x}) \cdot 100]$ assay coefficients of variation were 15.5 and $6.0 \%$, respectively. We routinely obtained a similar equation for the calibration curve $\left(\mathrm{IR}=55.10^{-5}+0.048 \cdot[\mathrm{Cu}, \mathrm{mg} / \mathrm{L}]\right)$, and the statistical analyses demonstrated a correlation coefficient always between 0.95 and 0.99. In addition, we explored the so-called matrix effects that could have modified the slopes of the standard regressions. In spiked samples the obtained values varying from 48 to $60.10^{-5}$ were very similar to those of $\mathrm{Cu}$ standard solutions, indicating that the matrix effect was not significant or was negligible. The mean for recovery and RSD for spiked samples was $99.7 \%$ and $3.3 \%$, respectively, and the detection limit was $0.09 \mathrm{mg} / \mathrm{L}$. In order to verify the accuracy of the method, we explored the influence of time after dilution, temperature of acid digestion, and concentration of $\mathrm{HNO}_{3} / \mathrm{HClO}_{4}$ following the suggestions of Terrés-Martos et al. [32]. We also checked our results with biological samples (plasma and homogenates) against a Seronorm Trace Elements Serum (from Sero Labs, Billingstad, Norway) and found no significant differences between the obtained and the declared (certified) concentrations.

2.6. Ceruloplasmin (CRP) Levels and NonceruloplasminBound Copper (NCBC). Samples were analyzed by the enzyme conversion of $\mathrm{p}$-phenylenediamine into a blue-colored product [33] which was then measured at $550 \mathrm{~nm}$. Reaction proceeded at $37^{\circ} \mathrm{C}$ in buffer glacial acetic/sodium acetate (50 mM, pH 5.5) directly into flat-bottomed plates, using a Microplate Reader SpectraMax M2/m2 $2^{e}$ model from Molecular Devices Analytical Technologies (Sunnyvale, CA, USA) for $3 \mathrm{~min}$. Intra- and interassay coefficients of variation were 8.3 and $4.4 \%$, respectively. CRP concentrations were calculated by comparison with the reaction rate of pure CRP standard (Sigma Chem. Co., Buenos Aires, Argentina). Using the $\mathrm{Cu}$ and $\mathrm{CRP}$ data, we calculated the non-CRP-bound $\mathrm{Cu}$ (NCBC, or so-called free $\mathrm{Cu}$ ) as described by Brewer [3] by subtracting the amount of $\mathrm{Cu}$ bound to each mg of CRP from data of total $\mathrm{Cu}$. This parameter can be easily expressed in percentages using the formula $(([\mathrm{Cu}]-47.2 \times[\mathrm{CRP}]) \times$ $100 /[\mathrm{Cu}])$, where $\mathrm{Cu}$ is in $\mu \mathrm{mol} / \mathrm{L}$ and CRP is in $\mathrm{g} / \mathrm{L}$ [34].

2.7. Lipid Analysis. Total lipids were extracted by the method of Folch et al. [35]. Aliquots of this solution were taken to measure total Cho by an enzymatic method using a commercial kit from Wienner Lab (Rosario, Argentina). To estimate the amount of esterified Cho (ECho), aliquots of the lipid extracts were seeded in high-resolution pre-coated silica gel plates $(10 \times 20 \mathrm{~cm})$ with a concentration zone for thin layer chromatography (Whatman Adsorption $60 \AA$ Silica Gel HP-TLC Plates, CA, USA) and developed with diethyl ether:hexane:acetic acid (90:4:1, by vol) as described elsewhere [36]. Authentic standards of Cho and Cho-esthers (from Avanti Polar Lipids, Ontario, Canada) were run in parallel and revealed by iodine vapors. Identified zones were scraped off the plates, eluted with Folch reactive, evaporated, dissolved in $50 \mathrm{mM}$ phosphate buffer ( $\mathrm{pH}$ 7.4) with $1 \%$ sodium deoxycholate, and enzymatically analyzed using the commercial kits from Wienner Lab (Rosario, Argentina).

2.8. Biomarkers of ROS Production. Thiobarbituric acidreactive substances (TBARS) were measured in brain homogenates as previously described [37]. TBARS (mainly malondialdehyde, MDA) reacted with 2-thiobarbituric acid (TBA) 
to yield TBA-MDA adducts which were quantified at $532 \mathrm{~nm}$. The concentration of the chromophore was calculated from a calibration curve prepared with fresh tetramethoxypropane (TMP) solutions (TMP was purchased from Sigma Chem. Co., Buenos Aires, Argentina). Nitrate and nitrite [NOx] concentration were measured using the method of Griess on samples previously reduced with vanadium chlorohydrate according to Miranda et al. [38]. Quantification was performed after calibration with standard solutions of sodium nitrate from Merck Co. (Darmstadt, Germany). Protein carbonyls (PCs) were determined by the method of Reznick and Packer [39]. The concentrations of PCs were calculated from a calibration curve prepared with a stock solution of sodium pyruvate (Sigma Chem. Co.).

\subsection{Antioxidant Defense System}

2.9.1. Reduced (GSH) and Oxidized (GSSG) Glutathione Content. Total glutathione was determined by the glutathione reductase/dithionitrobenzoic (DTNB) method that can measure both GSH and GSSG [40]. To calculate the GSH/GSSG ratio, samples were reanalyzed after derivatization with divinylpyridine (3 $\mathrm{mM}$ final concentration).

2.9.2. Vitamin E ( $\alpha$-tocopherol). Vitamin E ( $\alpha$-tocopherol) was measured after extraction with the Buttriss and Diplock method [41] using the HPLC technique of Bagnati et al. [42] in a reverse phase/C-18 silica column from ALLTECH Associates, Inc. (Deerfield, IL, USA). The ECONOSIL $\mathrm{C}_{18}$ column with a Direct-connect Cartridge Guard Column System was operated at a maximum pressure of $500 \mathrm{psi}$ in a Hitachi HPLC System (Tokyo, Japan). The amount of vitamin was electronically calculated using internal calibration with pure $\alpha$-tocopherol (Sigma, Bs. As.), and the results were expressed in $\mu \mathrm{M}$ concentration of $\alpha$-tocopherol.

2.9.3. Glutathione Reductase (GR). GR activity was determined by the method of Carlberg and Mannervik [43]. The specific activity of the enzyme was calculated for each sample in terms of $\mathrm{U} / \mathrm{min} \cdot \mathrm{mg}$ protein $\left(\varepsilon=6.22 \mathrm{nM}^{-1} \cdot \mathrm{cm}^{-1}\right.$ for absorbance at $340 \mathrm{~nm}$ ).

2.10. Biomarkers of Inflammation. Prostaglandin F $2 \alpha$ (PG F2 $\alpha$ ) and prostaglandin E2 (PGE2) were measured using the PGF $2 \alpha$ EIA Kit and PGE2 Express EIA Kit, respectively (Cayman, Migliore Laclaustra S.R). The results were expressed as ng of each prostaglandin/mg total protein.

\subsection{Programmed Cell Death Biomarkers}

2.11.1. Caspase-3 Activity. Caspase-3 activity was measured by a colorimetric assay kit (CASP-3-C) based on the hydrolysis of the synthetic peptide substrate acetyl-Asp-Glu-Val-Asp-pnitroaniline (Ac-DEVD-pNA) by caspase-3 (Sigma Chem. Co., Buenos Aires, Argentina). The resulting p-nitroaniline (p-NA) was monitored at $405 \mathrm{~nm}$. Each assay was run in parallel with inhibitor-treated homogenates (to measure the nonspecific hydrolysis of the substrate) and caspase- 3 positive control (using commercial caspase-3, $5 \mathrm{mg} / \mathrm{mL}$ provided by the kit manufacturer). A calibration curve using a standard solution of $\mathrm{p}$-nitroaniline ( $\mathrm{p}$-NA) was also run for each assay to calculate the activity of the protease expressed as $\mu \mathrm{mol} \mathrm{p}$ $\mathrm{NA}$ released $/ \mathrm{min} \cdot \mathrm{mg}$ protein.

2.11.2. Milli- ( $\left.m^{-}\right)$and Micro- $\left(\mu^{-}\right)$Calpains. The assay involves the hydrolysis of whole ultrapure casein (Sigma, Chem. Co., CA, USA) by calpain activity and the subsequent detection of trichloroacetic acid (TCA) soluble peptidic fragments at $280 \mathrm{~nm}$ [44]. To select the activity of the calpain isoforms, the level of calcium in the medium was regulated ( $5 \mathrm{mM}$ or $500 \mu \mathrm{M}$ of $\mathrm{CaCl}_{2}$ for $\mathrm{m}$ - or $\mu$-calpain, resp.). The activity of calpains was calculated considering that a unit of calpain is the amount of enzyme that produces a change of absorbance of 0.01 at $280 \mathrm{~nm}$. Results were expressed as units/min.mg of protein.

\subsection{Markers of Neurodegeneration}

2.12.1. Beta Amyloid Peptides (1-40) and (1-42). Beta amyloid peptides $(\mathrm{A} \beta)$ (1-40) and (1-42) were measured using Human/Rat $\beta$ Amyloid-40 ELISA kit Wako II and the Human Amyloid-42 ELISA kit Wako High-Sensitivity, respectively. The $\mathrm{A} \beta(1-42) /(1-40)$ ratio was then calculated from the individual data expressed as picomole of the respective $A \beta$ peptide/mg total protein.

2.12.2. Barnes Maze Test. The Barnes maze is a black acrylic circular platform, $122 \mathrm{~cm}$ in diameter and elevated $108 \mathrm{~cm}$ off the floor, containing twenty holes around the periphery. The $10 \mathrm{~cm}$ diameter holes are uniform in appearance but, one hole is connected to an escape box, consisting of a $38.7 \mathrm{~cm}$ long $\times 12.1 \mathrm{~cm}$ wide $\times 14.2$ depth $\mathrm{cm}$ removable box. Four proximal visual cues $(30 \mathrm{~cm}$ high, opaque black geometric figures: a cross, a circle, a square, and a triangle) were located in the room $50 \mathrm{~cm}$ from the circular platform. The escape box remained in a fixed position relative to the cues, to ensure randomization of the hole associated with the escape tunnel. In the center of the platform is a starting chamber (an opaque, $26 \mathrm{~cm}$ diameter, $20 \mathrm{~cm}$ high, and white plastic openended cylinder). A $90 \mathrm{~dB}$ white-noise generator and a whitelight $500 \mathrm{~W}$ bulb provided motivation for escaping from the platform. The acquisition session and the probe trial session were performed on the same day. In brief, the experiment consisted of eight acquisition trials (t1-t8) followed by a single evaluation trial ( $\mathrm{t} 9$ ). Acquisition trials began with the animal inside the starting chamber for 30 seconds in the presence of a constant buzz. The chamber was then raised, the aversive stimulus (intense bright light) was switched on, and the rat was allowed to freely explore the maze. The rats were each given $120 \mathrm{~s}$ to locate the correct hole. If by the end of this period they had not entered the escape box of their own accord, they were gently picked up and placed over the hole above the escape box. The evaluation trial proceeded in the same manner as described above but without the start box. At the end of each trial, the aversive stimulus was switched off, the rat remained on the escape box during $60 \mathrm{~s}$, and the white light was switched off. In order to eliminate any possible olfactory clues from the maze, it was cleaned with 
TABLE 1: Copper $(\mathrm{Cu})$ levels in animals fed with the experimental diets.

\begin{tabular}{|c|c|c|c|c|c|c|}
\hline \multirow{4}{*}{ Diets } & \multicolumn{6}{|c|}{$\mathrm{Cu}$ (ng/mg prot) } \\
\hline & \multicolumn{2}{|c|}{ Plasma } & \multicolumn{4}{|c|}{ Brain } \\
\hline & \multirow{2}{*}{ Total } & \multirow{2}{*}{ NCBC } & \multicolumn{2}{|c|}{ Cortex } & \multicolumn{2}{|c|}{ Hippocampus } \\
\hline & & & Total & NCBC & Total & NCBC \\
\hline Control & $18.5 \pm 0.8^{\mathrm{a}}$ & $0.95 \pm 0.11^{\mathrm{a}}$ & $5.5 \pm 0.2^{\mathrm{a}}$ & $0.25 \pm 0.04^{\mathrm{a}}$ & $4.8 \pm 0.1^{\mathrm{a}}$ & $0.27 \pm 0.04^{\mathrm{a}}$ \\
\hline $\mathrm{Cu}$ & $23.2 \pm 0.7^{\mathrm{b}}$ & $1.76 \pm 0.15^{\mathrm{b}}$ & $7.1 \pm 0.1^{\mathrm{b}}$ & $0.27 \pm 0.02^{\mathrm{a}}$ & $6.1 \pm 0.1^{b}$ & $0.33 \pm 0.02^{\mathrm{b}}$ \\
\hline Cho & $18.1 \pm 1.0^{\mathrm{a}}$ & $0.91 \pm 0.05^{\mathrm{a}}$ & $5.4 \pm 0.2^{\mathrm{a}}$ & $0.24 \pm 0.04^{\mathrm{a}}$ & $5.1 \pm 0.2^{\mathrm{a}}$ & $0.25 \pm 0.04^{\mathrm{a}}$ \\
\hline CuCho & $22.9 \pm 0.6^{\mathrm{b}}$ & $1.78 \pm 0.10^{\mathrm{b}}$ & $7.0 \pm 0.1^{\mathrm{b}}$ & $0.29 \pm 0.03^{\mathrm{a}}$ & $6.2 \pm 0.04^{\mathrm{b}}$ & $0.35 \pm 0.03^{\mathrm{b}}$ \\
\hline
\end{tabular}

$\mathrm{Cu}$ content was determined after mineral digestion of the samples by atomic absorption spectrometry as described in Section 2.5. Results are the mean of 10 independent measurements analyzed in triplicate \pm SD. Comparisons between data were performed by ANOVA + Tukey test at $P<0.01$. Statistical differences among the experimental diets were indicated with distinct superscript letters (values within the same column with different superscript letters are statistically significant between them).

TABLE 2: Esterfied (ECho) and free (FCho) cholesterol levels in animals fed with the experimental diets.

\begin{tabular}{|c|c|c|c|c|c|c|c|c|c|}
\hline \multirow{4}{*}{ Diets } & \multicolumn{9}{|c|}{ Cho (nmoles/mg.prot) } \\
\hline & \multirow{2}{*}{\multicolumn{3}{|c|}{ Plasma }} & \multicolumn{6}{|c|}{ Brain zones } \\
\hline & & & & \multicolumn{3}{|c|}{ Cortex } & \multicolumn{3}{|c|}{ Hippocampus } \\
\hline & Esterified & Free & FCho/Echo & Esterified & Free & FCho/Echo & Esterified & Free & FCho/Echo \\
\hline $\mathrm{C}$ & $16.4 \pm 0.3^{\mathrm{a}}$ & $10.6 \pm 0.2^{\mathrm{a}}$ & $0.64 \pm 0.05^{\mathrm{a}}$ & $28.2 \pm 1.9^{\mathrm{a}}$ & $257.8 \pm 10.6^{\mathrm{a}}$ & $9.14 \pm 0.71^{\mathrm{a}}$ & $28.7 \pm 2.2^{\mathrm{a}}$ & $247.1 \pm 9.7^{\mathrm{a}}$ & $8.61 \pm 0.60^{\mathrm{a}}$ \\
\hline $\mathrm{Cu}$ & $16.8 \pm 0.4^{\mathrm{a}}$ & $11.7 \pm 0.3^{\mathrm{a}}$ & $0.70 \pm 0.05^{\mathrm{a}}$ & $35.8 \pm 2.2^{\mathrm{b}}$ & $260.2 \pm 7.3^{\mathrm{a}}$ & $7.26 \pm 0.42^{\mathrm{b}}$ & $39.2 \pm 1.8^{\mathrm{b}}$ & $252.1 \pm 11.4^{\mathrm{a}}$ & $6.43 \pm 0.33^{\mathrm{b}}$ \\
\hline Cho & $22.2 \pm 0.4^{\mathrm{b}}$ & $11.5 \pm 0.4^{\mathrm{a}}$ & $0.51 \pm 0.03^{c}$ & $30.6 \pm 2.1^{\mathrm{a}}$ & $281.3 \pm 12.2^{b}$ & $9.19 \pm 0.55^{\mathrm{a}}$ & $28.0 \pm 1.7^{\mathrm{a}}$ & $269.4 \pm 11.4^{\mathrm{b}}$ & $9.62 \pm 0.21^{\mathrm{c}}$ \\
\hline CuCho & $18.3 \pm 0.5^{\mathrm{a}}$ & $15.5 \pm 0.5^{\mathrm{c}}$ & $0.85 \pm 0.05^{\mathrm{d}}$ & $70.0 \pm 3.1^{c}$ & $225.3 \pm 15.0^{c}$ & $3.21 \pm 0.13^{c}$ & $77.5 \pm 2.7^{\mathrm{c}}$ & $233.6 \pm 11.5^{\mathrm{a}}$ & $3.01 \pm 0.11^{\mathrm{d}}$ \\
\hline
\end{tabular}

Cho and Cho-esters contents were determined enzymatically after HP-TLC as described in Section 2.7. Results are the mean of 10 independent measurements analyzed in triplicate \pm SD. Comparisons between data were performed by ANOVA + Tukey test at $P<0.01$. Statistical differences among the experimental diets were indicated with distinct superscript letters (values within the same column with different superscript letters are statistically significant between them).

$10 \%$ ethyl alcohol solution at the beginning of the $15 \mathrm{~min}$ intertrial period. An individual hole exploration was defined as being a single downward head deflection toward the inside of the hole. The following parameters were determined: (i) first-hole latency time (in s) spent by the animal between being released from the start box and exploring a hole in the maze for the first time; (ii) escape-box latency time (defined in the acquisition and retention test trials as the time (in s) spent by the animal between being released from the start box and entering the escape box and, in the case of the preference test and extinction trials, the time elapsed before the first exploration of the escape hole); and (iii) nongoal hole exploration (defined as the number of explorations of holes other than the escape hole, the explorations being considered as errors during the acquisition and probe trials). In the case of the evaluation trials, we evaluated the hole exploration frequency (the number of explorations of each hole during the trial in which the escape hole was numbered as hole 0 for normalized graphical representation purposes, 1 to 10 clockwise, and -1 to -9 counterclockwise). The behavioral measurements were recorded using a video camera mounted $110 \mathrm{~cm}$ above the platform, linked to a computer. The video performances of each rat were analyzed using the video analysis software Kinovea-Creative Commons Attribution ( $\mathrm{v}$ 0.7.6).

2.13. Statistical Analysis. All values represent the mean of 6 rats assayed in triplicate expressed as mean \pm standard deviation (SD). Data were analyzed by ANOVA plus Tukey test with the aid of SPSS 11.0.1 software (SPSS Inc., Chicago, IL). To analyze the data from the Barnes maze test, multiple comparisons were drawn with the control group using twoway ANOVA plus the Holm-Sidak post hoc test at two levels of significance $(P<0.05$ and 0.01$)$. Data were also analyzed using MANOVA with identical final conclusions. Results were also plotted and analyzed using Sigma Scientific Graphing Software (version 11.0) from Sigma Chem. Co. (St. Louis, $\mathrm{MO}$ ). The statistical significance of differences is indicated by distinct superscript letters (data with distinct superscript letters are statistically different $(P<0.01)$ between them).

\section{Results}

3.1. Cholesterol and Copper Levels. Table 1 shows the levels of total and free $\mathrm{Cu}$ (NCBC or nonceruloplasmin-bound $\mathrm{Cu}$ ) in plasma and in brain cortex and hippocampus after the experimental treatments. Plasma total $\mathrm{Cu}$ and NCBC exhibited discrete (but statistically significant) increases in those groups receiving $\mathrm{Cu}(\mathrm{Cu}$ and $\mathrm{CuCho})$. Total $\mathrm{Cu}$ also increased in both cortex and hippocampus after $\mathrm{Cu}$ supplementation (alone or in combination with Cho). Cortex shows a nonsignificant tendency towards higher NCBC after $\mathrm{Cu}$ or CuCho treatments, whereas hippocampus shows a significant increase in this parameter with respect to the control group.

The results of the Cho analysis (free and esterified) are shown in Table 2, from which it is evident that tissue from 


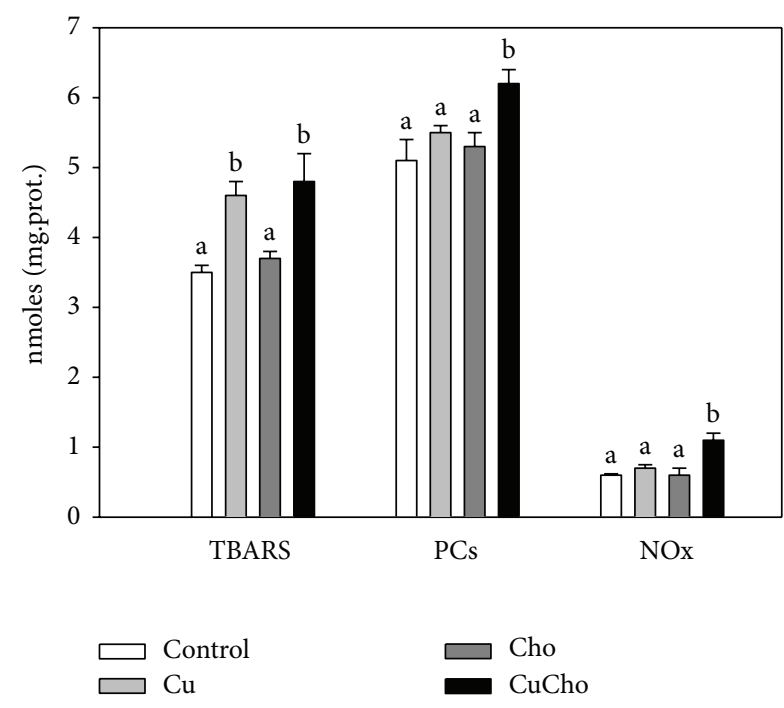

(a)

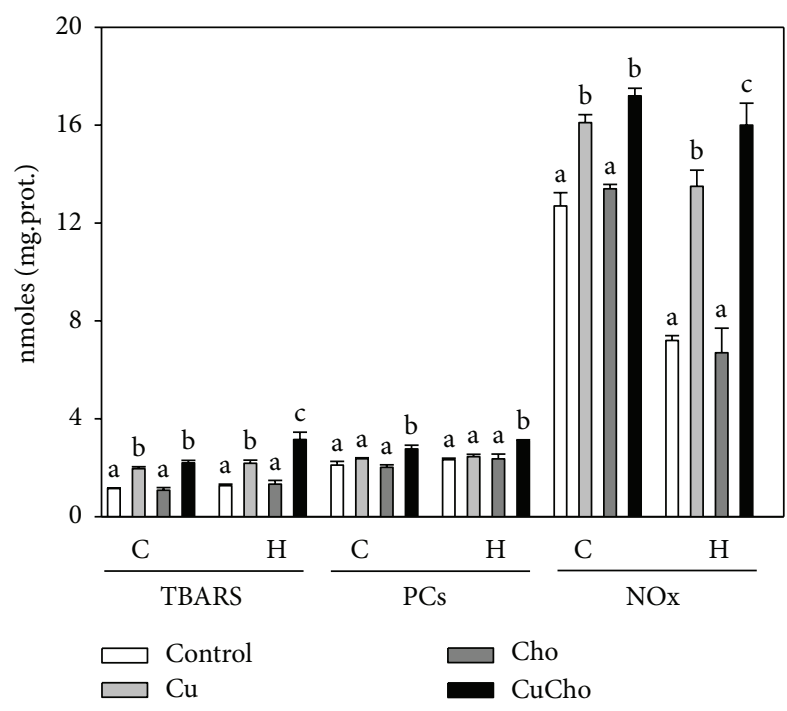

(b)

FIGURE 1: Oxidative/nitrative stress biomarkers in plasma (a) and brain cortex and hippocampus (b). Lipid peroxidation (TBARS) (nmol $\mathrm{MDA} / \mathrm{mg}$ protein), protein oxidation (PCs) (nmol MDA/mg protein), and concentration of nitrites and nitrates ([NOx]) ( $\mu \mathrm{mol} / \mathrm{mg} \mathrm{protein})$ were determined in plasma and brain cortex and hippocampus following the procedures described in described in Material and Methods Section. Treatments are indicated with different colors. Control (white bars), Cu (gray bars), Cho (dark gray bars), and CuCho (black bars). Results are expressed as mean of 10 rats assayed in triplicate \pm standard deviation (SD). Significant differences were indicated by letters (data with distinct letters are statistically different between them at $P<0.01$ ).

the central nervous system has a particular Cho metabolism characterized by higher levels of free Cho ( 25 times higher than in the case of plasma). Samples from brain and plasma behave differently from one another. $\mathrm{Cu}$ addition to drinking water produced no significant changes in plasma total Cho and a slight increase in cortex and hippocampus at the expense of the esterified form (ECho). Furthermore, $\mathrm{Cu}$ did not change the ratio between free and ECho in plasma samples but did lower this parameter in the brain homogenates. Supplementing food with Cho caused a higher level of total Cho in peripheral plasma (from $27.0 \pm 0.5$ in the control group to $33.7 \pm 0.6 \mathrm{nmoles} / \mathrm{mg}$ protein in Chosupplemented rats) with a slight but significant decrease in the proportion of free/Echo. In brain, all the treatments led to an increase in total (free + esterified) Cho with respect to control data, though the increase was substantially higher and differentially orchestrated in those groups receiving Cho supplementation. In the case of Cho-treated rats, this occurred at the expense of free Cho; however, in rats under $\mathrm{CuCho}$ treatment, it was at the expense of the ECho form. Under $\mathrm{CuCho}$ treatment, hippocampus reached even higher values of total Cho than cortex (approx. 311 versus 295 nmoles/mg protein). Addition of $\mathrm{Cu}$ alone significantly elevated the ECho in both brain tissues, more noticeably in hippocampus than in cortex. Another differential result for the CuCho group was a decrease in free Cho with respect to control rats in cortex, a phenomenon not observed in hippocampus. The results obtained for the ratios between free and ECho strongly suggest that $\mathrm{Cu}$ addition was able to modify the balance of these two parameters, triggering the accumulation of ECho in cortex and hippocampus, perhaps facilitating its esterification or impeding its degradation, or both. This effect is especially noticeable under conditions of simultaneous $\mathrm{Cu}$ and $\mathrm{Cho}$ overload and, even more interestingly, was contrary to the effect observed in peripheral plasma samples.

3.2. Biomarkers of Oxidative Stress. In order to detect whether inorganic $\mathrm{Cu}$ in drinking water and $\mathrm{Cho}$ in food produced oxidative/nitrative stress, we measured the oxidation end products of lipids (TBARS) and proteins (PCs) and also the levels of NOx (nitrates and nitrites derived from the spontaneous dismutation of nitric oxide) as biomarkers of damage. Levels of the three markers analyzed were higher after $\mathrm{CuCho}$ treatment both in plasma and in brain cortex and hippocampus (Figures 1(a) and 1(b)). In plasma, treatment with $\mathrm{Cu}$ alone increased TBARS levels (Figure 1(a)), whereas all three biomarkers were significantly increased after $\mathrm{CuCho}$ cosupplementation. Brain homogenates exhibited similar results, with increased levels of all three biomarkers after $\mathrm{Cu}$ or CuCho supplementation (with the solo exception of PCs in both brain regions, which increased only with simultaneous exposure to $\mathrm{Cu}$ and $\mathrm{Cho}$ ).

We also measured the levels of the two main antioxidant molecules for water- and lipid-soluble cellular compartments (total glutathione-GSH+GSSG- and $\alpha$-tocopherol, resp.) (Table 3). Plasma levels of total glutathione were higher in rats fed on $\mathrm{Cu}$ plus Cho supplements. In the same experimental group (CuCho), the $\alpha$-tocopherol concentration was $27 \%$ lower than in the control data. In brain cortex, we also observed an increase in total glutathione after $\mathrm{CuCho}$ treatments and a simultaneous increment in the GSSG/GSH ratio as a consequence of a higher level of GSSG. Concomitantly, the activity of glutathione reductase (GR) in cortex was 


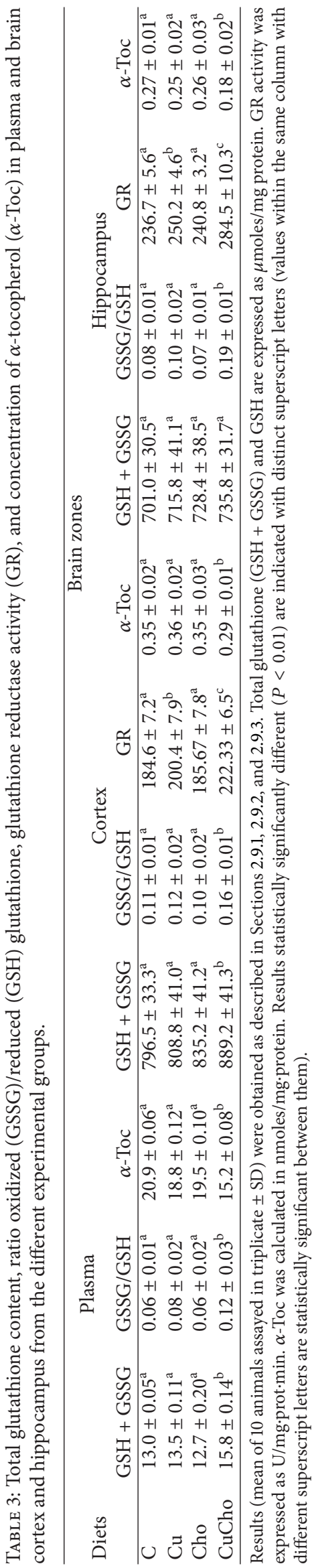




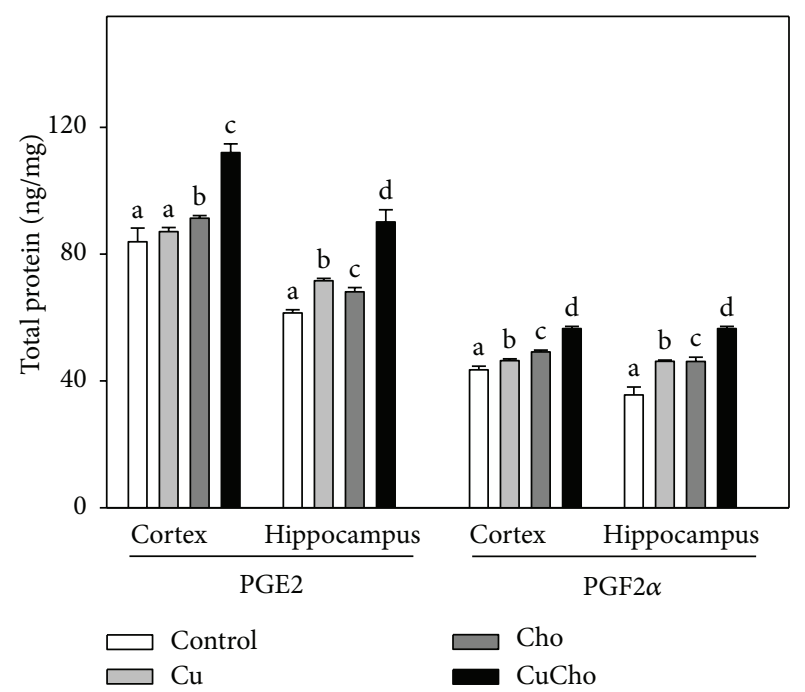

Figure 2: Prostaglandin PGF2 $\alpha$ and PGE2 levels in brain cortex and hippocampus homogenates (ng/mg total protein). Treatments are indicated with different colors. Samples were analyzed as indicated in Section 2.10. Control (white bars), Cu (gray bars), Cho (dark gray bars), and CuCho (black bars). Results are expressed as mean of 10 rats assayed in triplicate \pm standard deviation (SD). Significant differences were indicated by letters (data with distinct letters are statistically different between them at $P<0.01$ ).

enhanced by $\mathrm{Cu}$ supplementation and even more so by simultaneous treatment with $\mathrm{Cu}+\mathrm{Cho}$. The level of $\alpha$-tocopherol $(\alpha-\mathrm{Toc})$ decreased significantly only after CuCho treatment (approx. 17\% compared to control data). In hippocampus, the behavior was very similar, with the exception of the increment in total glutathion content. Thus, hippocampus homogenates showed a significant increase in the GSSG/GSH ratio, activation of $\mathrm{GR}$ in $\mathrm{Cu}$ - and $\mathrm{CuCho-treated} \mathrm{rats,} \mathrm{and}$ a ca. $34 \%$ decrease in $\alpha$-Toc content compared to control data, with this latter being observed only in the CuCho experimental group.

3.3. Markers of Inflammation. In order to evaluate whether simultaneous supplementation with $\mathrm{Cu}$ and Cho also produced an inflammatory condition, we analyzed the levels of two proinflammatory prostaglandins, PGE2 and PGF2 $\alpha$ (Figure 2). In both brain regions, cosupplementation significantly increased prostaglandin levels. Interestingly, $\mathrm{Cu}$ and Cho alone also increased prostaglandins levels with respect to control data, and association of the two supplements produced an additive effect.

3.4. Caspase-3 and Calpains Activities. We also explored whether the prooxidative and proinflammatory environment developed after $\mathrm{CuCho}$ treatment was able to trigger apoptotic signals, to which end we determined the activities of the two main protease systems involved in programmed cell death, caspase-3, and calpains ( $\mu$ - and $\mathrm{m}$-). Caspase-3 activity tends to increase at least in cortex homogenates, but not to a statistically significant degree (Figure 3 ). Both calpain (milliand microisoforms) activities increased after $\mathrm{Cu}$ treatment

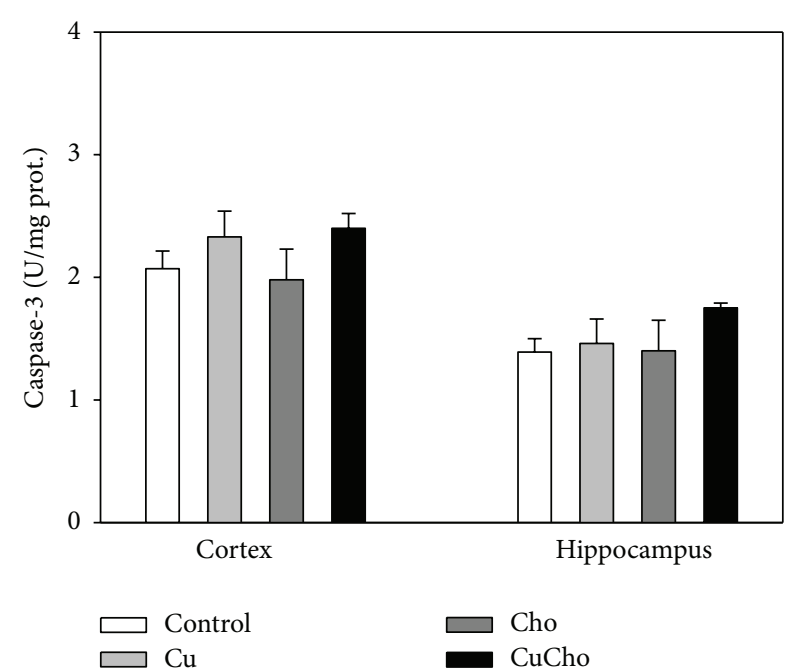

FIgURE 3: Caspase-3 (U/mg total protein) activity in brain cortex and hippocampus homogenates. Samples were analyzed according to the procedure described in Section 2.11.1. Treatments are indicated with different colors. Control (white bars), $\mathrm{Cu}$ (gray bars), Cho (dark gray bars), and CuCho (black bars). Results are expressed as mean of 10 rats assayed in triplicate \pm standard deviation (SD). There are no statistically significant differences $(P<0.01)$ between treatments.

and even more so after CuCho supplementation in both brain zones (Figure 4).

3.5. Biomarkers of Neurodegeneration. The concentration of the $\beta$-amyloid peptides (1-42 and 1-40) and the $\mathrm{A} \beta 1-42 / 1-40$ ratio in cortex and hippocampus are shown in Table 4 . The ratio (which is the main indicator of neurodegenerative process) was different, depending on the brain zone examined. In cortex, it was found to increase after $\mathrm{Cu}$ and Cho treatments and to further increase after $\mathrm{CuCho} \mathrm{supplementation.} \mathrm{In} \mathrm{hip-}$ pocampus, the $A \beta 42 / 40$ ratio increased only in the CuCho experimental group. There were no statistically significant changes of the ratio (1-42)/(1-40) in peripheral plasma.

We also investigated possible alterations in the visuospatial learning capabilities through the Barnes maze test. We observed minor (not statistically different) changes in latency to the first hole and more spatial preference for the escape region (holes $-1,0$, and 1) regardless of treatment (data not shown). Taken together, these changes demonstrate minor alterations in visuospatial memory suggesting that simultaneous supplementation with $\mathrm{Cu}$ and Cho produces an increment in exploratory activity-or a sort of overexcited behavior-but with similar final results to those observed in the other experimental groups.

\section{Discussion}

Supplementation of drinking water with low amounts of inorganic $\mathrm{Cu}$ such as those used in our experiments was able to modify the basal status of redox biomarkers not only in peripheral plasma but also in the two zones of the central nervous system explored, cortex and hippocampus. 


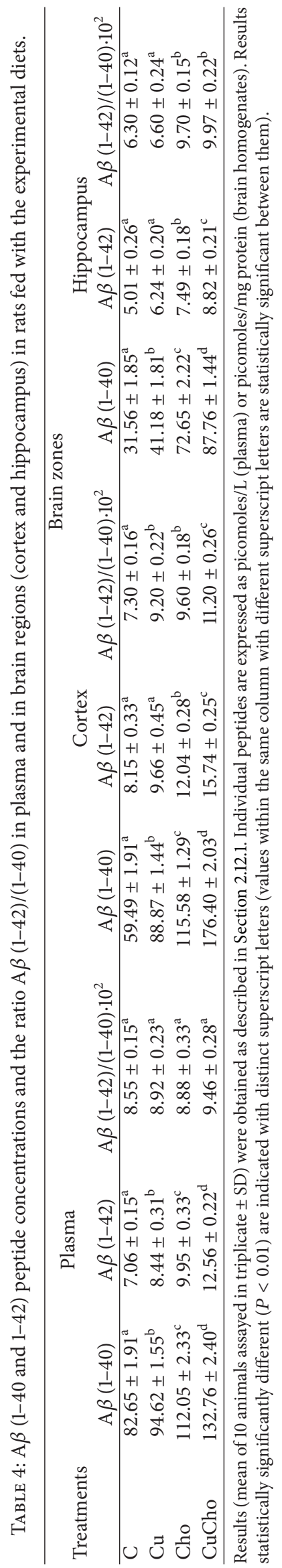




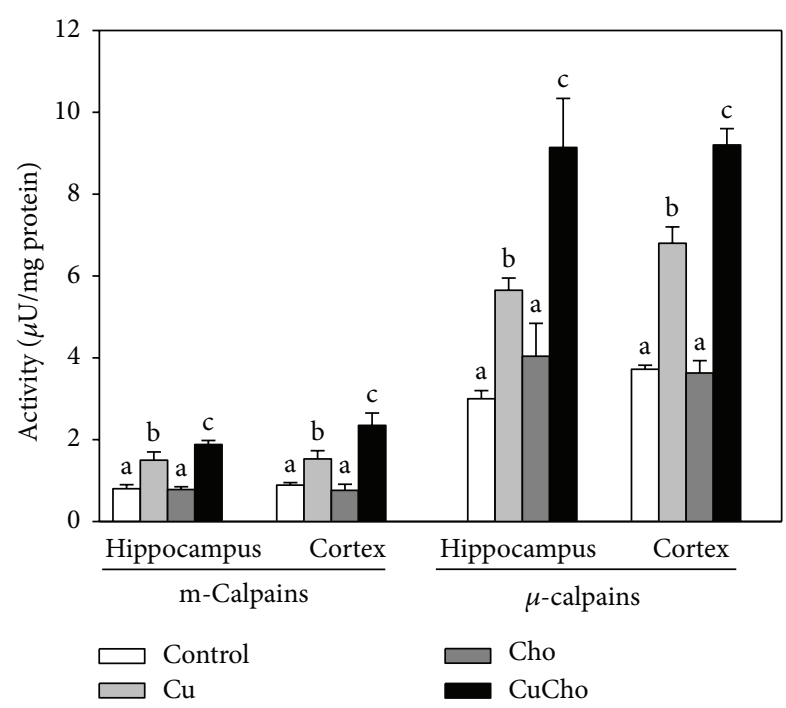

FIgURE 4: Calpains ( $\mu$ - and $\mathrm{m}$-) (U/min.mg total protein) activities in brain cortex and hippocampus homogenates. Samples were analyzed according to the procedures described in Section 2.11.2. Treatments are indicated with different colors. Control (white bars), $\mathrm{Cu}$ (gray bars), Cho (dark gray bars), and CuCho (black bars). Results are expressed as mean of 6 rats assayed in triplicate \pm standard deviation (SD). Significant differences were indicated by letters (data with distinct letters are statistically different between them at $P<0.01)$.

Because of their short life span, free radicals cannot be measured directly, for which reason it is usual to analyze the products arising from reactions caused by reactive species with biomolecules. In line with this, we measured the endoxidation products of lipids (TBARS) and proteins (PCs) and the production of NOx as biomarkers of prooxidative tissue damage. PCs increased only after CuCho treatment; however, TBARS and NOx increased after a sole exposure to trace amounts of inorganic $\mathrm{Cu}$ in drinking water. The biomarkers assayed were reproducible and sensitive to the experimental stimuli. Many authors have associated neurodegenerative illnesses with both a local (brain) and a systemic (plasma) increase in oxidative stress [45-52]. Irrespective of whether biomarkers are causative factors or whether they merely constitute phenomenologically associated changes, they are useful tools for evaluating the extent of damage and provide a simple methodology for monitoring large populations subjected to environmental $\mathrm{Cu}$ pollution or exposed to other risks associated with the development of AD. There is abundant evidence that transition metals in general, and specially $\mathrm{Cu}$, are causative factors for oxidative stress and, as we mentioned previously, are strongly associated with the neurodegenerative process [53-56].

The decrease of $\alpha$-tocopherol in plasma and brain zones homogenates and the increased GSSG/GSH ratio are both markers of accumulation of reactive species in lipid- and water-soluble cell compartments. The activation of GR can be interpreted as a compensatory mechanism of the enzymatic antioxidant defense system in order to normalize the altered GSSG/GSH ratio induced by cotreatment with $\mathrm{Cu}$ and Cho.
In agreement with our results, Kojima et al. [57] have demonstrated the induction of mRNA coding for GR in the brain of mice irradiated with a low dose of $\gamma$-rays. Also in line with this, we can speculate that the observed increase in plasma total glutathione levels may be due to a compensatory mechanism under the oxidative insult evoked by the treatment studied here. This explanation is in agreement with the suggestions of other authors [58] and may be the consequence of an induction (overexpression) of cysteinyl-synthetase, the enzyme that controls the biosynthesis of glutathione $[59,60]$.

The oxidative stress induced by NCBC could have multiple effects on the signals cascade that depends on the redox state and can also modify the activity of ionic channels, transporters, and enzymes. Pallottini et al. [61] observed, in liver of Wistar rats treated with thioacetamide, that HMGCoAreductase overactivation was strictly related to the magnitude of the reactive species accumulated. Our results demonstrate that inorganic $\mathrm{Cu}$ supplementation-even at the low levels assayed-produced an increase in ECho levels in cortex and hippocampus. Attributing the increase in Cho in brain to oxidative stress-induced HMGCoA-reductase hyperactivity could be oversimplistic, and this intriguing question remains to be resolved on the basis of new experimental evidence. Cho in the nervous system (10-fold higher than in any other organ) is mainly unesterified $[62,63]$. Furthermore, most of the Cho content in brain depends on the in situ biosynthesis that appears to be regulated by similar mechanisms both outside and inside the brain, with HMGCoA-reductase being the most important regulatory effector [63]. However, the exact extent of Cho biosynthesis in neurons and astrocytes in vivo remains unknown [62], making it difficult to estimate the real effect of the accumulation of reactive species (NCBC-induced) on brain Cho biosynthesis. Interestingly, Cho turnover in individual neurons and astrocytes may in fact be very high and reach an estimated $20 \%$ per day, depending on the brain zone [62]. Unfortunately, the direct effect of higher Cho levels in blood on Cho concentration in brain is difficult to assess. Cho trafficking between brain and peripheral blood implies the participation of the bloodbrain barrier (BBB) that hinders the direct passage into or out of the central nervous system. However, for reasons not yet understood, this restriction appears to be reduced in $\mathrm{AD}$ and other neurodegenerative disorders [64]. Also, in certain circumstances, for example, in cases of vascular injury due to oxidative stress, the BBB could be permeable to interaction with the peripheral pool of Cho [64]. Moreover, recent experimental evidence in a mouse model of $\mathrm{AD}$ demonstrated that inflammation is one of the key factors in determining increased $\mathrm{BBB}$ vulnerability [65]. Thus, from the above, we can assume that peripheral Cho might cross the BBB into the brain, in particular when the tissue is subjected to oxidative stress and redox-induced inflammation as observed in our experimental model.

Despite extensive research in recent years, the role of Cho as a risk factor for $\mathrm{AD}$ remains controversial [64], likely due to the still unresolved questions relating to the exact role of peripheral Cho in its level in brain. We can speculate that NCBC induces nitrative/oxidative and proinflammatory conditions that probably facilitate endothelial 
damage and indirectly modify $\mathrm{BBB}$ properties $[64,65]$, allowing peripheral Cho to enter the central nervous system. Obviously, a great deal of experimental work is still required to either confirm or refute this working hypothesis. Several unresolved issues raise doubts concerning the beneficial effects of statins in neurodegenerative patients and the notion that high blood Cho is associated with brain dysfunction. However, one possibility is that the real risk is the association of hypercholesterolemia with a prooxidative and proinflammatory environment induced, for example, by NCBC.

Brain Cho is involved in synaptogenesis, the turnover, maintenance, stabilization, and restoration of synapses [63]. The functionality of synapses requires specific lipid domains in neuronal and axon membranes whose composition is critical for the correct targeting of the major membrane proteins, myelin biogenesis, cellular differentiation, signal transduction, and many other functions that depend on microdomains and specific lipid rafts. The proportion of free Cho to ECho in these membrane domains is a crucial factor in their biological activities [63]. For example, the enzymes responsible for the processing of the amyloid precursor protein (APP) to $\mathrm{A} \beta$ ( $\beta$ - and $\gamma$-secretases) reside in Cho-rich lipid rafts of plasma membrane [66]. It was suggested that a higher total Cho/phospholipid ratio in cellular membranes could affect secretase activities and determine preferential APP processing pathways [66], though in vitro studies suggest that Cho might impair the transcription of APP and consequently decrease the availability for its conversion to $\beta \mathrm{A}$. However, it appears that this effect has no significant impact on the amount of protein (that still exceeds the capacity of the secretase system to process it) and only a slight impact on the levels of the mRNA encoding APP protein [67]. To date, there are no findings elucidating the exact role of ECho and how the ratio of free to esterified forms is able to modify secretase activity and other process associated with the amyloidogenic cascade [63]. Zana et al. [45] suggest that different sources of oxidative stress, such as NCBC, could trigger the amyloidogenic pathway, which may explain the higher $\mathrm{A} \beta$ 1-42/1-40 ratio we observed in the brain cortex of $\mathrm{Cu}$-treated rats and in the group receiving both treatments (CuCho).

The question as to how Cho and $\mathrm{Cu}$ interact to lower the production of $\beta \mathrm{A}$ and enhance oxidative stress and inflammation is difficult to address. Experimental evidence obtained in culture cells demonstrates that exposure of macrophages to $\mathrm{CuSO}_{4}$, at a level equivalent to NCBC in humans, induces SREBP-2 and consequently the expression of cholesterogenic enzymes [68], thus tentatively providing a new explanation for the apparently additive effect we observed between $\mathrm{Cu}$ and Cho. However, we were unable to find similar evidence in neuron or astrocyte cultures, or even in experiments conducted on live animals to explore these findings. There is yet another possibility: that the association of the two supplements ( $\mathrm{Cu}$ and $\mathrm{Cho}$ ) may affect the clearance of $\beta \mathrm{A}$ and facilitate its accumulation. Working with rabbits fed on a diet with excess Cho and inorganic $\mathrm{Cu}$ in their drinking water, Sparks et al. [69] proposed that Cho caused alterations in the BBB associated with an inflammatory condition and a concomitant overproduction of $\beta \mathrm{A}$ in the brain.
In this model, $\mathrm{Cu}$ decreased the clearance of $\beta \mathrm{A}$ to the blood via inhibition of LRP at the vascular interface [69]. Impaired Cho metabolism, oxidative stress, and inflammation were all factors associated with the decreased clearance of the $\beta$ A peptide $[63,69]$. In addition, Lu et al. [14] also demonstrated that $\mathrm{Cu}$ exacerbates $\beta \mathrm{A}$ amyloid-induced neurotoxicity through a TNF-mediated inflammatory pathway.

Though the exact mechanism(s) underlying all these effects is still unknown, it is nevertheless widely accepted that the $\mathrm{AD}$ pathological cascade is likely to be a 2-stage event where deposition of $\beta \mathrm{A}$ and neuronal pathology (tauopathy, neuronal injury, and programmed cell death, or subsequent neurodegeneration with synapse and cognitive loss) are sequential rather than simultaneous processes [70, 71]. Our model likely represents a very early step in these successive events since the screening of the damages observed in visuospatial memory revealed only slight modifications. The Barnes maze test analysis demonstrated that all groups display almost normal locomotor and exploratory activities and spatial memory retention. The behavioral modifications indicate that the animals of the control and Cho groups were fully able to acquire the necessary knowledge for the spatial task through training, whereas the $\mathrm{Cu}$ and $\mathrm{CuCho}$ groups were only partially able to do so or presented slight learning difficulties. Interestingly, these learning difficulties were more evident during the evaluation trials of Cho animals, which explored holes very distant from the escape-hole region. Nevertheless, Cho and $\mathrm{CuCho}$ animals both showed a minor degree (not statistically significant) of deficit in learning and spatial memory capabilities.

Plasma levels of $\beta \mathrm{A}$, particularly the $\beta \mathrm{A} 1-40 / \beta \mathrm{A} 1-42$ ratio, are well-recognized biomarkers of sporadic $\mathrm{AD}[72,73]$ and even indicators of early stages of the pathology [74]. However, apart from its role as a biomarker, accumulation of $\beta \mathrm{A}$ peptide in brain is a complex phenomenon with multiple and consecutive (sometimes unexpected) consequences [75]. In agreement with this, Tamagno et al. [76] demonstrated that oxidative stress induced by $\mathrm{A} \beta 25-35$ resulted in an early, significant, and time-dependent generation of free $\mathrm{HNE}$ (hydroxyl-nonenal) and $\mathrm{H}_{2} \mathrm{O}_{2}$. Also, other authors reported increased levels of oxidative stress biomarkers after $\mathrm{A} \beta$ exposure both in vivo and in vitro [77-79]. Our results are therefore in agreement with those of other groups reporting that oxidative stress and $\mathrm{A} \beta$ are linked to one another. Apparently, A $\beta$ can induce oxidative stress [80, 81], and prooxidants such as NCBC can increase $\mathrm{A} \beta$ production [82-84] in the manner of an autostimulated process.

The increased levels of the two main proinflammatory prostaglandins (E2 and F2 $\alpha$ ) are consistent with the inflammatory condition characteristic of AD [85]. This proinflammatory and prooxidative environment triggers the activation of calpains, whereas caspase-3 activity was not significantly stimulated under our experimental conditions. In previous papers, we also found such dissociation between the effects of inorganic $\mathrm{Cu}$ overload on the relative activities of the two protease systems, which-at least in vitro experimentsappear to depend on the extent and intensity of exposure to $\mathrm{Cu}$ overload [86]. However, in view of previous experimental evidence, we cannot conclude that neuronal death is actually 
occurring. So far, Saito et al. [87] have reported that the activation of $\mu$-calpains in $\mathrm{AD}$ brain is not necessarily a consequence of the endstage of neuronal degeneration and may reflect a more widespread metabolic alteration that precedes and contributes to neuronal death. In fact, they observed increased activity of $\mu$-calpains in the cerebellum of $\mathrm{AD}$ without any increase in the rate of death neurons [87]. In line with this, Nixon [88] established that different factors could lead to calpain activation triggering neurodegeneration in the early stages of $\mathrm{AD}$ development. Moreover, Trinchese et al. [89] also reported that calpains have many substrates that could be affected in AD patients but do not necessarily lead to immediate cell death. They also stated that $\mu$-calpains are present predominantly in synapses, which is in agreement both with the fact that $\mathrm{Cu}$ concentration is particularly high (micromolar) in the synaptic cleft [90] and with the wellestablished synaptic pathology in AD [90, 91]. Nixon [88] suggested that increased activity of calpains during normal aging may also promote the development of neurological disorders and impaired calcium homeostasis, both of which could impact on the role of this cation in the function of cellular membrane receptors and metallosignaling in brain [91].

Finally, in discussing the validity and/or limitations of our experimental system, it is necessary to consider the level of the supplementation with $\mathrm{Cu}$ using oral administration. Our experimental conditions were based on previous work $[13,14]$ and resemble the $\mathrm{Cu}$ levels commonly found as a consequence of involuntary exposure through air, food and water pollution [16, 92-94], ingestion of dietary mineral supplements, exposure of professionals engaged in agrochemical activities [6, 11, 95], neurodegenerative patients and their first-degree relatives, or female users of $\mathrm{Cu}$-based intrauterine devices $[17,19]$. Studies performed in rats demonstrated that $\mathrm{Cu}$ metabolism and homeostasis are essentially identical to those in humans [96]. In terms of dosage, the rats from the groups supplemented with $\mathrm{Cu}$ received $1.06 \pm 0.11 \mathrm{mg}$ $\mathrm{Cu} / \mathrm{Kg}$ /day (including $\mathrm{Cu}$ acquire from food and water ingestion). From the available data in humans, we can assume that general population are receiving 0.16 to 0.98 EAR or RDA which is equivalent to 0.3 to $1.5 \mathrm{mg} \mathrm{Cu} / \mathrm{kg}$ body weight [97]. Very probably, humans are exposed to several types of $\mathrm{Cu}$-based compounds of different chemical structures with differences in their physical stabilities, solubility, absorption capacities, life's times into the organism, and many other particularities related to their excretion or bioaccumulation rates. However, only inorganic $\mathrm{Cu}$ should be dangerous for its probable role as causative factor for neurodegeneration $[3,6,8-10]$. Thus, we think that there are a lot of questions to be answered before drawing a realistic conclusion about the comparisons between our experimental conditions and the actual human expose to $\mathrm{Cu}$.

\section{Conclusions}

In conclusion, this in vivo study reveals that the association of inorganic $\mathrm{Cu}$ and $\mathrm{Cho}$ gives rise to a prooxidative and proinflammatory environment more pronounced than that produced by $\mathrm{Cu}$ and Cho administered alone. As described before, the combination of these two factors is common in many human populations. We suggest that the biochemical changes observed, in particular, oxidative stress, inflammation, and the higher $A \beta 1-42 / 1-40$ ratio in the cortex of rats fed on $\mathrm{Cu}+\mathrm{Cho}(\mathrm{CuCho})$, could constitute the initial stages of the development of neurodegenerative disease. In view of the abundant evidence of disturbed $\mathrm{Cu}$ homeostasis in $\mathrm{AD}[7,56,98,99]$, we strongly recommend more indepth studies on the mechanism(s) responsible for the proneurodegenerative effect(s) of the association between NCBC and Cho. Furthermore, it is recommended that the present experimental evidence be used to promote the investigation of the emerging biomarkers-such as those examined in this work-to be applied in peripheral plasma as predictive tool(s) in high-risk populations.

\section{Conflict of Interests}

All authors disclose any financial and personal relationships with other people or organizations that could inappropriately influence this work. The authors declare that there is no conflict of interests.

\section{Acknowledgments}

This study was supported by a Grant from Consejo Nacional de Investigaciones Científicas y Técnicas (CCT-CONICET) PIP \#0697 and UNLP/M-145. We would like to thank Norma Cristalli, Cristina Pallanza, and Eva Illara de Bozzolo for their excellent technical assistance.

\section{References}

[1] L. E. Hebert, P. A. Scherr, J. L. Bienias, D. A. Bennett, and D. A. Evans, "Alzheimer disease in the US population: prevalence estimates using the 2000 census," Archives of Neurology, vol. 60, no. 8, pp. 1119-1122, 2003.

[2] P. M. Bagnati, R. F. Allegri, J. Kremer, and F. E. Taragano, Enfermedad de Alzheimer y Otras Demencias, Ed. Polemos, 2010.

[3] G. J. Brewer, "Issues raised involving the copper hypotheses in the causation of Alzheimer's disease," International Journal of Alzheimer's Disease, vol. 2011, Article ID 537528, 11 pages, 2011.

[4] H. D. Foster, "Why the preeminent risk factor in sporadic Alzheimer's disease cannot be genetic," Medical Hypotheses, vol. 59, no. 1, pp. 57-61, 2002.

[5] C. Salustri, G. Barbati, R. Ghidoni et al., "Is cognitive function linked to serum free copper levels? A cohort study in a normal population," Clinical Neurophysiology, vol. 121, no. 4, pp. 502507, 2010.

[6] G. J. Brewer, "Copper toxicity in Alzheimer's disease: cognitive loss from ingestion of inorganic copper," Journal of Trace Elements in Medicine and Biology, vol. 26, no. 2-3, pp. 89-92, 2012.

[7] R. Squitti, R. Ghidoni, F. Scrascia et al., "Free copper distinguishes mild cognitive impairment subjects from healthy elderly individuals," Journal of Alzheimer's Disease, vol. 23, no. 2, pp. 239-248, 2011.

[8] R. Squitti, P. Pasqualetti, G. dal Forno et al., "Excess of serum copper not related to ceruloplasmin in Alzheimer disease," Neurology, vol. 64, no. 6, pp. 1040-1046, 2005. 
[9] R. Squitti, G. Barbati, L. Rossi et al., "Excess of nonceruloplasmin serum copper in AD correlates with MMSE, CSF $\beta$-amyloid, and h-tau," Neurology, vol. 67, no. 1, pp. 76-82, 2006.

[10] R. Squitti, F. Bressi, P. Pasqualetti et al., "Longitudinal prognostic value of serum "free" copper in patients with Alzheimer disease," Neurology, vol. 72, no. 1, pp. 50-55, 2009.

[11] N. Arnal, D. O. Cristalli, M. J. T. de Alaniz, and C. A. Marra, "Clinical utility of copper, ceruloplasmin, and metallothionein plasma determinations in human neurodegenerative patients and their first-degree relatives," Brain Research, vol. 1319, pp. 118-130, 2010.

[12] D. L. Sparks and B. G. Schreurs, "Trace amounts of copper in water induce $\beta$-amyloid plaques and learning deficits in a rabbit model of Alzheimer's disease," Proceedings of the National Academy of Sciences of the United States of America, vol. 100, no. 19, pp. 11065-11069, 2003.

[13] J. Lu, Y.-L. Zheng, D.-M. Wu, D.-X. Sun, Q. Shan, and S.-H. Fan, "Trace amounts of copper induce neurotoxicity in the cholesterol-fed mice through apoptosis," FEBS Letters, vol. 580, no. 28-29, pp. 6730-6740, 2006.

[14] J. Lu, D.-M. Wu, Y.-L. Zheng et al., “Trace amounts of copper exacerbate beta amyloid-induced neurotoxicity in the cholesterol-fed mice through TNF-mediated inflammatory pathway," Brain, Behavior, and Immunity, vol. 23, no. 2, pp. 193-203, 2009.

[15] P. S. Donnelly, Z. Xiao, and A. G. Wedd, "Copper and Alzheimer's disease," Current Opinion in Chemical Biology, vol. 11, pp. 128-133, 2007.

[16] K. A. Cockell, J. Bertinato, and M. R. L’Abbé, "Regulatory frameworks for copper considering chronic exposures of the population," American Journal of Clinical Nutrition, vol. 88, no. 3, pp. 863S-866S, 2008.

[17] N. Arnal, M. J. T. de Alaniz, and C. A. Marra, "Alterations in copper homeostasis and oxidative stress biomarkers in women using the intrauterine device TCu380A," Toxicology Letters, vol. 192, no. 3, pp. 373-378, 2010.

[18] N. Arnal, M. Astiz, M. J. T. de Alaniz, and C. A. Marra, "Clinical parameters and biomarkers of oxidative stress in agricultural workers who applied copper-based pesticides," Ecotoxicology and Environmental Safety, vol. 74, no. 6, pp. 1779-1786, 2011.

[19] D. de la Cruz, A. Cruz, M. Arteaga, L. Castillo, and H. Tovalin, "Blood copper levels in Mexican users of the T380A IUD," Contraception, vol. 72, no. 2, pp. 122-125, 2005.

[20] W. B. Grant, "Dietary links to Alzheimer's disease," Alzheimer's Disease Review, vol. 2, pp. 42-55, 1997.

[21] M. A. Pappolla, M. A. Smith, T. Bryant-Thomas et al., "Cholesterol, oxidative stress, and Alzheimer's disease: expanding the horizons of pathogenesis," Free Radical Biology \& Medicine, vol. 33, no. 2, pp. 173-181, 2002.

[22] G. Di Paolo and T.-W. Kim, "Linking lipids to Alzheimer's disease: cholesterol and beyond," Nature Reviews Neuroscience, vol. 12, no. 5, pp. 284-296, 2011.

[23] M. Stefani and G. Liguri, "Colesterol in Alzheimer's disease: unresolved questions," Current Alzheimer Research, vol. 6, pp. $1-17,2009$.

[24] B. Schreurs, "The effects of cholesterol on learning and memory," Neuroscience \& Biobehavioral Reviews, vol. 34, no. 8, pp. 1366-1379, 2010.

[25] M. C. Morris, D. A. Evans, C. C. Tangney et al., "Dietary copper and high saturated and trans fat intakes associated with cognitive decline," Archives of Neurology, vol. 63, no. 8, pp. 10851088, 2006.
[26] P. G. Reeves, F. H. Nielsen, and G. C. Fahey Jr., "AIN-93 purified diets for laboratory rodents: final report of the American Institute of Nutrition ad hoc writing committee on the reformulation of the AIN-76A rodent diet," Journal of Nutrition, vol. 123, no. 11, pp. 1939-1951, 1993.

[27] National Institute of Health, Guide for the Care and Use of Laboratory Animals, NIH Publication no. 85-23, National Research Council, Bethesda, Md, USA, 1985.

[28] K. A. Cockell, A. T. L. Wotherspoon, B. Belonje et al., "Limited effects of combined dietary copper deficiency/iron overload on oxidative stress parameters in rat liver and plasma," Journal of Nutritional Biochemistry, vol. 16, no. 12, pp. 750-756, 2005.

[29] C. D. Davis and S. Newman, "Inadequate dietary copper increases tumorigenesis in the Min mouse," Cancer Letters, vol. 159, no. 1, pp. 57-62, 2000.

[30] G. Paxinos and C. Watson, The Rat Brain in Stereotaxic Coordinates, Academic Press, Boston, Mass, USA, 4th edition, 1998.

[31] M. Berkovitch, E. Heyman, R. Afriat et al., "Copper and zinc blood levels among children with nonorganic failure to thrive," Clinical Nutrition, vol. 22, no. 2, pp. 183-186, 2003.

[32] C. Terrés-Martos, M. Navarro-Alarcón, F. Martín-Lagos, H. López-G de la Serrana, and M. C. López-Martínez, "Determination of copper levels in serum of healthy subjects by atomic absorption spectrometry," Science of The Total Environment, vol. 198, no. 1, pp. 97-103, 1997.

[33] S. Martínez-Subiela, F. Tecles, and J. J. Ceron, "Comparison of two automated spectrophotometric methods for ceruloplasmin measurement in pigs," Research in Veterinary Science, vol. 83, no. 1, pp. 12-19, 2007.

[34] P. J. Twomey, A. S. Wierzbicki, I. M. Hose, A. Viljoen, and T. M. Reynolds, "Percentage non-ceruloplasmin bound copper," Clinical Biochemistry, vol. 40, no. 9-10, pp. 749-750, 2007.

[35] J. Folch, M. Lees, and G. H. Sloane Stanley, "A simple method for the isolation and purification of total lipides from animal tissues," The Journal of Biological Chemistry, vol. 226, no. 1, pp. 497-509, 1957.

[36] C. A. Marra and M. J. T. De Alaniz, "Neutral and polar lipid metabolism in liver microsomes of growing rats fed a calciumdeficient diet," Biochimica et Biophysica Acta, vol. 1686, no. 3, pp. 220-237, 2005.

[37] K. Yagi, "A simple fluorometric assay for lipoperoxide in blood plasma," Biochemical Medicine, vol. 15, no. 2, pp. 212-216, 1976.

[38] K. M. Miranda, M. G. Espey, and D. A. Wink, "A rapid, simple spectrophotometric method for simultaneous detection of nitrate and nitrite," Nitric Oxide, vol. 5, no. 1, pp. 62-71, 2001.

[39] A. Z. Reznick and L. Packer, "Oxidative damage to proteins: spectrophotometric method for carbonyl assay," Methods in Enzymology, vol. 233, pp. 357-363, 1994.

[40] M. E. Anderson and A. Meister, "Enzymic assay of GSSG plus GSH," Methods in Enzymology, vol. 105, pp. 448-450, 1984.

[41] J. L. Buttriss and A. T. Diplock, "High-performance liquid chromatography methods for vitamin E in tissues," Methods in Enzymology, vol. 105, pp. 131-138, 1984.

[42] M. Bagnati, R. Bordone, C. Perugini, C. Cau, E. Albano, and G. Bellomo, "Cu(I) availability paradoxically antagonizes antioxidant consumption and lipid peroxidation during the initiation phase of copper-induced LDL oxidation," Biochemical and Biophysical Research Communications, vol. 253, no. 2, pp. 235240, 1998.

[43] I. Carlberg and B. Mannervik, "Glutathione reductase," Methods in Enzymology, vol. 113, pp. 484-490, 1985. 
[44] N. Botha, M. M. Gehringer, T. G. Downing, M. van de Venter, and E. G. Shephard, "The role of microcystin-LR in the induction of apoptosis and oxidative stress in $\mathrm{CaCo} 2$ cells," Toxicon, vol. 43, no. 1, pp. 85-92, 2004.

[45] M. Zana, Z. Janka, and J. Kálmán, "Oxidative stress: a bridge between Down's syndrome and Alzheimer's disease," Neurobiology of Aging, vol. 28, no. 5, pp. 648-676, 2007.

[46] D. Praticò, “Oxidative stress hypothesis in Alzheimer's disease: a reappraisal," Trends in Pharmacological Sciences, vol. 29, no. 12, pp. 609-615, 2008.

[47] F. Song, A. Poljak, G. A. Smythe, and P. Sachdev, "Plasma biomarkers for mild cognitive impairment and Alzheimer's disease," Brain Research Reviews, vol. 61, no. 2, pp. 69-80, 2009.

[48] F. Mangialasche, M. C. Polidori, R. Monastero et al., "Biomarkers of oxidative and nitrosative damage in Alzheimer's disease and mild cognitive impairment," Ageing Research Reviews, vol. 8, no. 4, pp. 285-305, 2009.

[49] A. Skoumalová and J. Hort, "Blood markers of oxidative stress in Alzheimer's disease," Journal of Cellular and Molecular Medicine, vol. 16, pp. 2291-2300, 2012.

[50] E. A. Kosenko, G. Aliev, L. A. Tikhonova, Y. Li, A. C. Poghosyan, and Y. G. Kaminsky, "Antioxidant status and energy state of erythrocytes in Alzheimer dementia: probing for markers," CNS \& Neurological Disorders-Drug Targets, vol. 11, no. 7, pp. 926932, 2012.

[51] N. López, C. Tormo, I. De Blas, I. Llinares, and J. Alom, "Oxidative stress in Alzheimer's disease and mild cognitive impairment with high sensitivity and specificity," Journal of Alzheimer's Disease, vol. 33, pp. 823-829, 2013.

[52] M. C. Badía, E. Giraldo, F. Dasí et al., "Reductive stress in young healthy individuals at risk of Alzheimer disease," Free Radical Biology \& Medicine, vol. 63, pp. 274-279, 2013.

[53] A. Campbell, M. A. Smith, L. M. Sayre, S. C. Bondy, and G. Perry, "Mechanisms by which metals promote events connected to neurodegenerative diseases," Brain Research Bulletin, vol. 55, no. 2, pp. 125-132, 2001.

[54] L. Rossi, R. Squitti, L. Calabrese, G. Rotilio, and P. M. Rossini, "Alteration of peripheral markers of copper homeostasis in Alzheimer's disease patients: implications in aetiology and therapy," Journal of Nutrition, Health and Aging, vol. 11, no. 5, pp. 408-417, 2007.

[55] J. H. Viles, "Metal ions and amyloid fiber formation in neurodegenerative diseases. Copper, zinc and iron in Alzheimer's, Parkinson's and prion diseases," Coordination Chemistry Reviews, vol. 256, no. 19-20, pp. 2271-2284, 2012.

[56] R. Squitti, "Metals in alzheimer's disease: a systemic perspective," Frontiers in Bioscience, vol. 17, no. 2, pp. 451-472, 2012.

[57] S. Kojima, O. Matsuki, T. Nomura et al., "Localization of glutathione and induction of glutathione synthesis- related proteins in mouse brain by low doses of $\gamma$-rays," Brain Research, vol. 808, no. 2, pp. 262-269, 1998.

[58] Y. Sharma, S. Bashir, M. Irshad, T. C. Nag, and T. D. Dogra, "Dimethoate-induced effects on antioxidant status of liver and brain of rats following subchronic exposure," Toxicology, vol. 215, no. 3, pp. 173-181, 2005.

[59] R. Dringen, "Metabolism and functions of glutathione in brain," Progress in Neurobiology, vol. 62, no. 6, pp. 649-671, 2000.

[60] R. Dringen, "Oxidative and antioxidative potential of brain microglial cells," Antioxidants and Redox Signaling, vol. 7, no. 9-10, pp. 1223-1233, 2005.
[61] V. Pallottini, C. Martini, A. M. Bassi, P. Romano, G. Nanni, and A. Trentalance, "Rat HMGCoA reductase activation in thioacetamide-induced liver injury is related to an increased reactive oxygen species content," Journal of Hepatology, vol. 44, no. 2, pp. 368-374, 2006.

[62] F. W. Pfrieger and N. Ungerer, "Cholesterol metabolism in neurons and astrocytes," Progress in Lipid Research, vol. 50, no. 4, pp. 357-371, 2011.

[63] V. Leoni and C. Caccia, "Oxysterols as biomarkers in neurodegenerative diseases," Chemistry and Physics of Lipids, vol. 164, no. 6, pp. 515-524, 2011.

[64] M. Stefani and G. Liguri, “Cholesterol in Alzheimer's disease: unresolved questions," Current Alzheimer Research, vol. 6, no. 1, pp. 15-29, 2009.

[65] S. Takeda, N. Sato, K. Ikimura, H. Nishino, H. Rakugi, and R. Morishita, "Increased blood-grain barrier vulnerability to systemic inflammation in an Alzheimer disease mouse model," Neurobiology of Aging, vol. 34, no. 8, pp. 2064-2070, 2013.

[66] J. Wang, K. Ohno-Matsui, and I. Morita, "Cholesterol enhances amyloid $\beta$ deposition in mouse retina by modulating the activities of $\mathrm{A} \beta$-regulating enzymes in retinal pigment epithelial cells," Biochemical and Biophysical Research Communications, vol. 424, no. 4, pp. 704-709, 2012.

[67] J. L. Galbete, T. Rodriguez-Martin, E. Peressini, P. Modena, R. Bianchi, and G. Forloni, "Cholesterol decreases secretion of the secreted form of amyloid precursor protein by interfering with glycosylation in the protein secretory pathway," Biochemical Journal, vol. 348, no. 2, pp. 307-313, 2000.

[68] P. A. Svensson, M. C. Englund, E. Markström et al., "Copper induces the expression of cholesterogenic genes in human macrophages," Atherosclerosis, vol. 169, no. 1, pp. 71-76, 2003.

[69] D. L. Sparks, C. Ziolkowski, T. Lawmaster, and T. Martin, "Influence of water quality on cholesterol-induced tau pathology: preliminary data," International Journal of Alzheimer's Disease, vol. 2011, Article ID 987023, 7 pages, 2011.

[70] C. R. Jack Jr., D. S. Knopman, W. J. Jagust et al., "Hypothetical model of dynamic biomarkers of the Alzheimer's pathological cascade," The Lancet Neurology, vol. 9, no. 1, pp. 119-128, 2010.

[71] C. R. Jack Jr., V. J. Lowe, S. D. Weigand et al., "Serial PIB and MRI in normal, mild cognitive impairment and Alzheimer's disease: implications for sequence of pathological events in Alzheimer's disease," Brain, vol. 132, part 5, pp. 1355-1365, 2009.

[72] H. Zetterberg, k. Blennow, and E. Hanse, "Amyloid beta and APP as biomarkers for Alzheimer's disease," Experimental Gerontology, vol. 45, no. 1, pp. 23-29, 2010.

[73] A. Tamaoka, T. Fukushima, N. Sawamura et al., "Amyloid $\beta$ protein in plasma from patients with sporadic Alzheimer' $s$ disease," Journal of the Neurological Sciences, vol. 141, no. 1-2, pp. 65-68, 1996.

[74] P. Lewczuk, J. Kornhuber, E. Vanmechelen et al., "Amyloid $\beta$ peptides in plasma in early diagnosis of Alzheimer's disease: a multicenter study with multiplexing," Experimental Neurology, vol. 223, no. 2, pp. 366-370, 2010.

[75] P. J. Crouch, S. M. Harding, A. R. White, J. Camakaris, A. I. Bush, and C. L. Masters, "Mechanisms of A beta mediated neurodegeneration in Alzheimer's disease," The International Journal of Biochemistry \& Cell Biology, vol. 40, no. 2, pp. 181198, 2008.

[76] E. Tamagno, G. Robino, A. Obbili et al., " $\mathrm{H}_{2} \mathrm{O}_{2}$ and 4-hydroxynonenal mediate amyloid $\beta$-induced neuronal apoptosis by activating JNKs and p38MAPK," Experimental Neurology, vol. 180, no. 2, pp. 144-155, 2003. 
[77] B. R. Ahn, H. E. Moon, H. R. Kim, H. A. Jung, and J. S. Choi, "Neuroprotective effect of edible brown alga Eisenia bicyclis on amyloid betapeptide-induced toxicity in PC12 cells," Archives of Pharmacal Research, vol. 35, no. 11, pp. 1989-1998, 2012.

[78] T. Luo, W. Jiang, Y. Kong et al., "The protective effects of jatrorrhizine on $\beta$-amyloid (25-35)-induced neurotoxicity in rat cortical neurons," CNS \& Neurological Disorders Drug Targets, vol. 11, no. 8, pp. 1030-1037, 2012.

[79] V. V. dos Santos, D. B. Santos, G. Lach et al., "Neuropeptide Y (NPY) prevents depressive-like behavior, spatial memory deficits and oxidative stress following amyloid- $\beta\left(\mathrm{A} \beta_{1-40}\right)$ administration in mice," Behavioural Brain Research, vol. 244, pp. 107115, 2013.

[80] T. Harkany, I. Abrahám, C. Kónya et al., "Mechanisms of beta-amyloid neurotoxicity: perspectives of pharmacotherapy," Reviews in the Neurosciences, vol. 11, no. 4, pp. 329-382, 2000.

[81] C.-A. Yang, Y.-H. Chen, S.-C. Ke et al., "Correlation of copper interaction, copper-driven aggregation, and copper-driven $\mathrm{H}_{2} \mathrm{O}_{2}$ formation with $\mathrm{A} \beta 40$ conformation," International Journal of Alzheimer's Disease, vol. 2011, Article ID 607861, 7 pages, 2011.

[82] D. Paola, C. Domenicotti, M. Nitti et al., "Oxidative stress induces increase in intracellular amyloid $\beta$-protein production and selective activation of $\beta$ I and $\beta$ II PKCs in NT2 cells," Biochemical and Biophysical Research Communications, vol. 268, no. 2, pp. 642-646, 2000.

[83] E. Tamagno, M. Parola, P. Bardini et al., " $\beta$-site APP cleaving enzyme up-regulation induced by 4 -hydroxynonenal is mediated by stress-activated protein kinases pathways," Journal of Neurochemistry, vol. 92, no. 3, pp. 628-636, 2005.

[84] C.-J. Lin, H.-C. Huang, and Z.-F. Jiang, "Cu(II) interaction with amyloid- $\beta$ peptide: a review of neuroactive mechanisms in $\mathrm{AD}$ brains," Brain Research Bulletin, vol. 82, no. 5-6, pp. 235-242, 2010.

[85] D. Galasko and T. J. Montine, "Biomarkers of oxidative damage and inflammation in Alzheimer's disease," Biomarkers in Medicine, vol. 4, no. 1, pp. 27-36, 2010.

[86] N. Arnal, M. J. de Alaniz, and C. A. Marra, "Cytotoxic effects of copper overload on human-derived lung and liver cells in culture," Biochimica et Biophysica Acta, vol. 1820, no. 7, pp. 931939, 2012

[87] K.-I. Saito, J. S. Elce, J. E. Hamos, and R. A. Nixon, "Widespread activation of calcium-activated neutral proteinase (calpain) in the brain in Alzheimer disease: a potential molecular basis for neuronal degeneration," Proceedings of the National Academy of Sciences of the United States of America, vol. 90, no. 7, pp. 26282632, 1993.

[88] R. A. Nixon, "The calpains in aging and aging-related diseases," Ageing Research Reviews, vol. 2, no. 4, pp. 407-418, 2003.

[89] F. Trinchese, M. Fa', S. Liu et al., "Inhibition of calpains improves memory and synaptic transmission in a mouse model of Alzheimer disease," The Journal of Clinical Investigation, vol. 118, no. 8, pp. 2796-2807, 2008.

[90] S. W. Scheff and D. A. Price, "Synaptic pathology in Alzheimer's disease: a review of ultrastructural studies," Neurobiology of Aging, vol. 24, no. 8, pp. 1029-1046, 2003.

[91] P. C. Amadoruge and K. J. Barnham, “Alzheimer's disease and metals: a review of the involvement of cellular membrane receptors in metallosignalling," International Journal of Alzheimer's Disease, vol. 2011, Article ID 542043, 9 pages, 2011.

[92] M. Costa, O. Cantoni, M. de Mars, and D. E. Swartzendruber, "Toxic metals produce an S-phase-specific cell cycle block,"
Research Communications in Chemical Pathology and Pharmacology, vol. 38, no. 3, pp. 405-419, 1982.

[93] R. Newhook, H. Hirtle, K. Byrne, and M. E. Meek, "Releases from copper smelters and refineries and zinc plants in Canada: human health exposure and risk characterization," Science of the Total Environment, vol. 301, no. 1-3, pp. 23-41, 2003.

[94] N. Arnal, M. J. de Alaniz, and C. A. Marra, "Involvement of copper overload in human diseases," in Metals in Biology Systems, pp. 1-28, Research Signpost, 2010.

[95] F. Y. Leung, "Trace elements in parenteral micronutrition," Clinical Biochemistry, vol. 28, no. 6, pp. 561-566, 1995.

[96] J. A. Cuthbert, "Wilson's disease: a new gene and an animal model for an old disease," Journal of Investigative Medicine, vol. 43, no. 4, pp. 323-336, 1995.

[97] I.-L. Notkola, R. Sulkava, J. Pekkanen et al., "Serum total cholesterol, apolipoprotein E $\varepsilon 4$ allele, and Alzheimer's disease," Neuroepidemiology, vol. 17, no. 1, pp. 14-20, 1998.

[98] R. Squitti, D. L. Sparks, T. U. Hoogenraad, and G. J. Brewer, "Copper status in Alzheimer's disease and other neurodegenerative disorders: genetics, mechanisms, neurophysiology, and therapies," International Journal of Alzheimer's Disease, vol. 2011, Article ID 903940, 2 pages, 2011.

[99] R. Squitti, “Copper dysfunction in Alzheimer's disease: from meta-anlysis of biochemical studies to new insight into genetics," Journal of Trace Elements in Medicine and Biology, vol. 26, no. 2-3, pp. 93-96, 2012. 


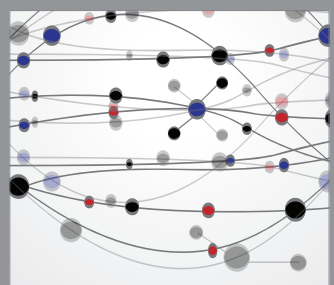

The Scientific World Journal
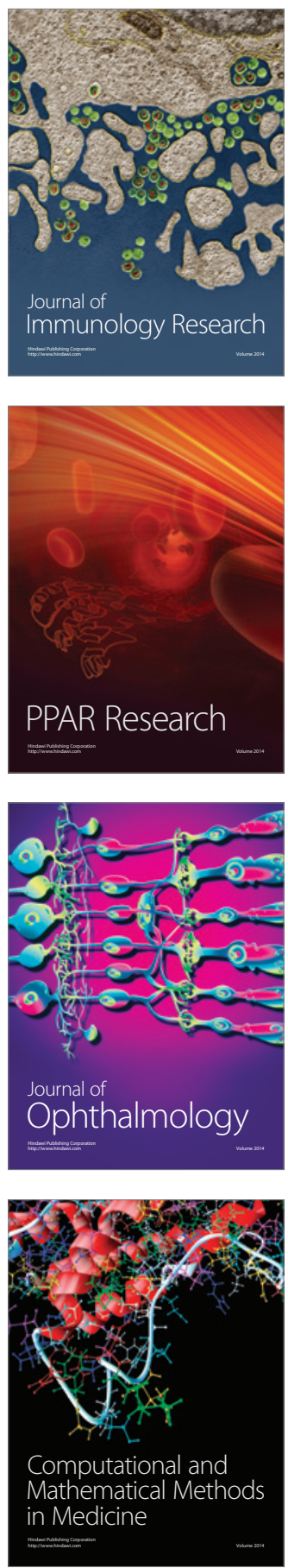

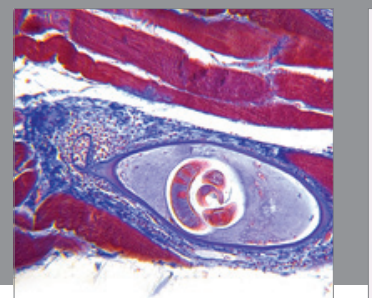

Gastroenterology

Research and Practice
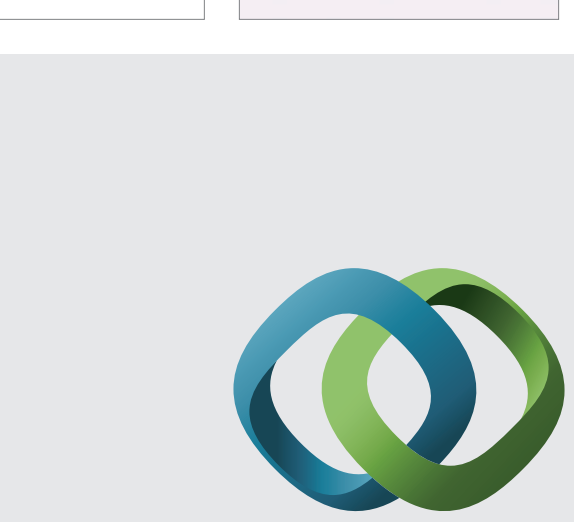

\section{Hindawi}

Submit your manuscripts at

http://www.hindawi.com
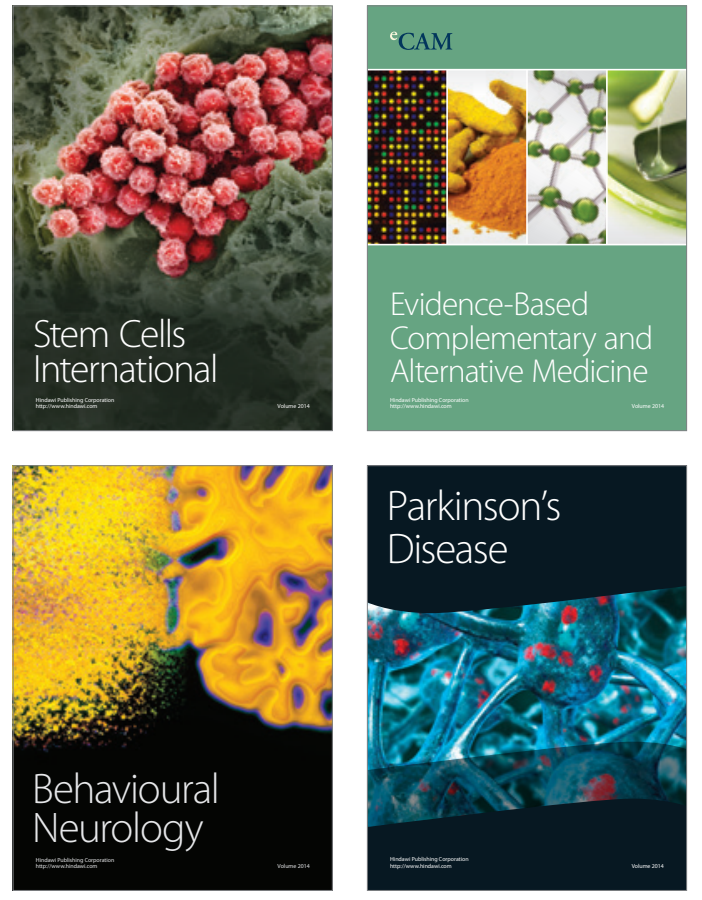
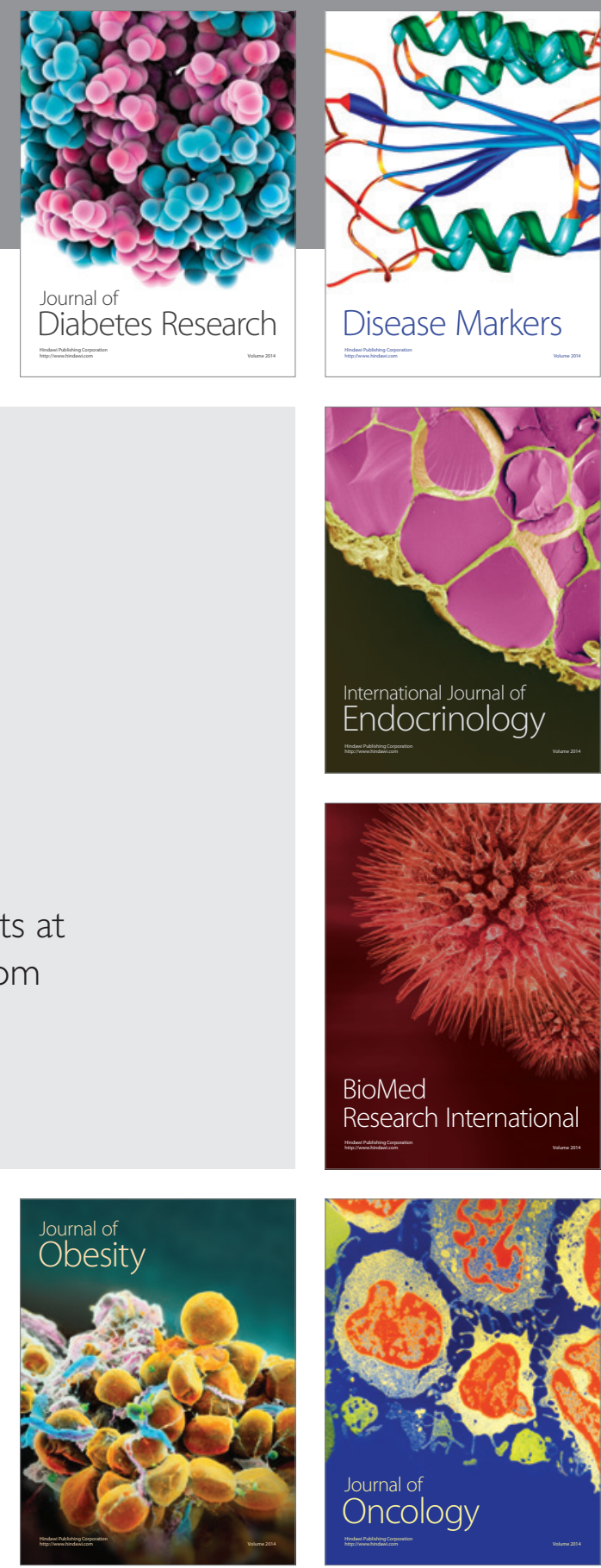

Disease Markers
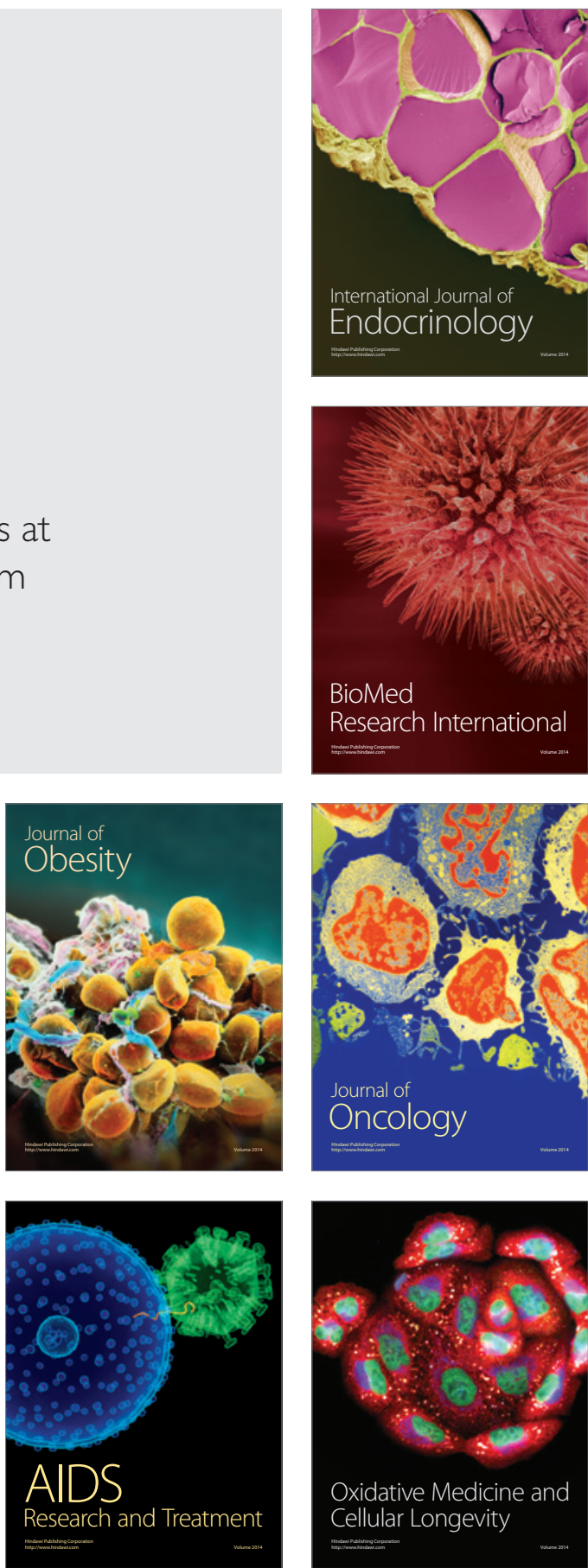